\title{
Hygroscopicity of organic compounds from biomass burning and their influence on the water uptake of mixed organic ammonium sulfate aerosols
}

\author{
T. Lei ${ }^{1,2}$, A. Zuend ${ }^{3}$, W. G. Wang ${ }^{1}$, Y. H. Zhang ${ }^{2}$, and M. F. Ge ${ }^{1}$ \\ ${ }^{1}$ Beijing National Laboratory for Molecular Sciences (BNLMS), State Key Laboratory for Structural Chemistry \\ of Unstable and Stable Species, Institute of Chemistry, Chinese Academy of Sciences, 100190, Beijing, China \\ ${ }^{2}$ The Institute of Chemical Physics, Key Laboratory of Cluster Science, \\ Beijing Institute of Technology, Beijing 100081, China \\ ${ }^{3}$ Department of Atmospheric and Oceanic Sciences, McGill University, Montreal, Quebec, Canada
}

Correspondence to: M. F. Ge (gemaofa@iccas.ac.cn) and A. Zuend (andreas.zuend@mcgill.ca)

Received: 24 April 2014 - Published in Atmos. Chem. Phys. Discuss.: 9 May 2014

Revised: 11 September 2014 - Accepted: 16 September 2014 - Published: 23 October 2014

\begin{abstract}
Hygroscopic behavior of organic compounds, including levoglucosan, 4-hydroxybenzoic acid, and humic acid, as well as their effects on the hygroscopic properties of ammonium sulfate (AS) in internally mixed particles are studied by a hygroscopicity tandem differential mobility analyzer (HTDMA). The organic compounds used represent pyrolysis products of wood that are emitted from biomass burning sources. It is found that humic acid aerosol particles only slightly take up water, starting at RH (relative humidity) above $\sim 70 \%$. This is contrasted by the continuous water absorption of levoglucosan aerosol particles in the range 5$90 \% \mathrm{RH}$. However, no hygroscopic growth is observed for 4-hydroxybenzoic acid aerosol particles. Predicted water uptake using the ideal solution theory, the AIOMFAC model and the E-AIM (with UNIFAC) model are consistent with measured hygroscopic growth factors of levoglucosan. However, the use of these models without consideration of crystalline organic phases is not appropriate to describe the hygroscopicity of organics that do not exhibit continuous water uptake, such as 4-hydroxybenzoic acid and humic acid. Mixed aerosol particles consisting of ammonium sulfate and levoglucosan, 4-hydroxybenzoic acid, or humic acid with different organic mass fractions, take up a reduced amount of water above $80 \% \mathrm{RH}$ (above AS deliquescence) relative to pure ammonium sulfate aerosol particles of the same mass. Hygroscopic growth of mixtures of ammonium sulfate and levoglucosan with different organic mass fractions agree well with the predictions of the thermodynamic models. Use of the Zdanovskii-Stokes-Robinson (ZSR) relation
\end{abstract}

and AIOMFAC model lead to good agreement with measured growth factors of mixtures of ammonium sulfate with 4-hydroxybenzoic acid assuming an insoluble organic phase. Deviations of model predictions from the HTDMA measurement are mainly due to the occurrence of a microscopical solid phase restructuring at increased humidity (morphology effects), which are not considered in the models. Hygroscopic growth factors of mixed particles containing humic acid are well reproduced by the ZSR relation. Lastly, the organic surrogate compounds represent a selection of some of the most abundant pyrolysis products of biomass burning. The hygroscopic growths of mixtures of the organic surrogate compounds with ammonium sulfate with increasing organics mass fraction representing ambient conditions from the wet to the dry seasonal period in the Amazon basin, exhibit significant water uptake prior to the deliquescence of ammonium sulfate. The measured water absorptions of mixtures of several organic surrogate compounds (including levoglucosan) with ammonium sulfate are close to those of binary mixtures of levoglucosan with ammonium sulfate, indicating that levoglucosan constitutes a major contribution to the aerosol water uptake prior to (and beyond) the deliquescence of ammonium sulfate. Hence, certain hygroscopic organic surrogate compounds can substantially affect the deliquescence point of ammonium sulfate and overall particle water uptake. 


\section{Introduction}

The hygroscopicity of aerosol particles plays a critical role in visibility degradation, cloud formation, radiative forcing and thereby regional and global climate (Sloane and Wolff, 1985; Charlson et al., 1992; Pandis et al., 1995; Heintzenberg and Charlson, 2009; Shi et al., 2012). Also, the hygroscopic properties of aerosols determine which fraction of aerosol particles can act as cloud condensation nuclei (CCNs) and thus contribute to the aerosol indirect effect (Pilinis et al., 1995; McFiggans, 2006; Hallquist et al., 2009). Moreover, water uptake by aerosol particles influences their health effects, as reported in epidemiological studies (Pöschl, 2005). Therefore, understanding the interactions between water vapor and aerosol particles, as well as the related physicochemical processes in the atmosphere is of great significance.

Biomass burning is one of the important sources of anthropogenic atmospheric aerosols and also leads to the emission of greenhouse gases. The annual globally burned land area is in the range of 3 to 3.5 million square kilometers, resulting in emissions amounting to $2.5 \times 10^{9} \mathrm{~kg}$ carbon per year (van der Werf et al., 2006; Schultz et al., 2008). Particles in biomass burning smoke enriched with hygroscopic organic and inorganic constituents are suggested to act as efficient cloud condensation nuclei (Novakov and Corrigan, 1996; Petters et al., 2009; Rissler et al., 2010; Dusek et al., 2011; Frosch et al., 2011). In the Amazon basin, for example, the CCN concentration in the dry season is 1 order of magnitude higher than in the wet season due to biomass burning (Roberts et al., 2001; Carrico et al., 2008; Hening et al., 2010). In addition, the aerosol indirect climatic effects resulting from increased cloud condensation nuclei concentrations are expected to be very important in tropical regions, particularly in the regions with very high biomass burning emissions (Roberts et al., 2001; Carrico et al., 2008; Hening et al., 2010). Increased CCN concentrations may lead to reduced average cloud droplet radii and associated with this, likely an enhanced negative radiative forcing of affected clouds (Roberts et al., 2003; Lohmann and Feichter, 2005; Dinar et al., 2006a, b, 2007; Carrico et al., 2008). Because of the complex chemical composition of biomass burning aerosols (Decesari et al., 2000, 2006; Shimmo et al., 2004), there is lack of qualitative as well as quantitative information on the detailed chemical composition and mixing state (i.e., internally or externally mixed aerosol populations and/or whether individual particles consist of a single, homogeneously mixed phase or multiple liquid/solid phases). Recently several groups have reported that a significant portion of particles in biomass burning (from $11 \%$ to as high as $99 \%$ by mass) consist of water-soluble organic carbon (WSOC) (Ruellan et al., 1999; Novakov and Corrigan, 1996; Narukawa et al., 1999; Hoffer et al., 2006; Iinuma et al., 2007; Fu et al., 2009; Claeys et al., 2010; Dusek et al., 2011; Psichoadaki and Pandis, 2013). One way to handle the large number of organic compounds comprised within the water-soluble atmospheric aerosol fraction is to identify a set of model substances that may be representative in reproducing the hygroscopic behavior of the water-soluble organic fraction of the real aerosol particles (May-Bracero et al., 2002; Rissler et al., 2010; Wu et al., 2011; Zamora and Jacobson, 2013). For example, based on the identification of model compounds with the help of chromatographic chemical separation, HNMR (proton nuclear magnetic resonance) analysis and TOC (total organic carbon) measurements, Andreae et al. (2002) studied the chemical composition of the WSOC fraction of particles generated by biomass burning and divided these detected WSOC into three different classes: (1) neutrals (N), (2) monocarboxylic and dicarboxylic acids (MDA), and (3) polycarboxylic acids (PA). Further, Artaxo et al. (2002) have suggested organic surrogate compounds representing size-resolved WSOC chemical composition for the dry and wet seasonal periods of their field campaign in Rondônia, Amazonia. On the basis of chemical structure, neutral compounds mainly consist of sugar-like compounds such as levoglucosan, which is the most abundant semivolatile product of the pyrolysis of cellulose (Iinuma et al., 2007; Claeys et al., 2010; Engling et al., 2013; Samburova et al., 2013). Another significant fraction of WSOC are aromatic acids like 4-hydroxybenzoic acid, which has been identified as a pyrolysis product of lignin, and which is a major constituent of woods (Mochida and Kawamura, 2004; Hoffer et al., 2006; Iinuma et al., 2007; Fu et al., 2009; Dusek et al., 2011; Psichoadaki and Pandis. 2013). Water-soluble organic carbon is also linked to a class of complex poly carboxylic acids, which are denoted by the generic term "HULIS" (humic-like substances) (Decesari et al., 2001; Fuzzi et al., 2001; Dinar et al., 2006a, b, 2007; Pope et al., 2010; Fors et al., 2010; Zamora et al., 2011). Also, an aerosol population can appear as externally mixed, heterogeneously internally mixed (i.e., coated or phase-separated particles) or homogeneously internally mixed (Riziq et al., 2008; Shamjad et al., 2012; Maskey et al., 2014). The mixing structure of atmospheric aerosols has a significant effect on their hygroscopicity (Chan et al., 2006; Maskey et al., 2014). For example, Chan et al. (2006) studied the hygroscopic behavior of solid ammonium sulfate coated with glutaric acid in two consecutive cycles of hydration and dehydration using an electrodynamic balance (EDB). They concluded that the different deliquescence behavior of mixed particles observed between the two cycles of hydration and dehydration was caused by the different mixing structures of particles (most likely, core-shell phase-separated, and well-mixed particles in the first and second cycles, respectively). In addition, it has been reported that water-soluble organic compounds from biomass burning, i.e., mono- and carboxylic acids, levoglucosan, and humic acid were quite abundant in the find mode $\left(D_{\mathrm{p}}<1.1 \mu \mathrm{m}\right)$ (Robert et al., 2003; Rissler et al., 2006; Vestin et al., 2007; Agarwal et al., 2010; Claey et al., 2010). Also, different effects of particles size (in the submicron size range) on the hygroscopic growth factors and deliquescence 
behavior of aerosol are reported in the literature (Hämer et al., 2000; Mirabel et al., 2000; Djikaev et al., 2001; Russell and Ming, 2002; Robert et al., 2003; Biskos et al., 2006a, b), especially for particles smaller than $100 \mathrm{~nm}$ in the diameter. For example, Biskos et al. (2006a, b) observed that the deliquescence and efflorescence of ammonium sulfate nanoparticles $(6-60 \mathrm{~nm})$ are similar to their larger-particle counterparts. The hygroscopic growth factors, however, decrease substantially with decreasing particles diameter from 60 to $6 \mathrm{~nm}$. In this study, particles of $\sim 100 \mathrm{~nm}$ dry diameter are used in our laboratory experiments, thus, albeit of interest, such size effects were not studied for our model mixtures.

Sampled WSOC typically contain a wide range of chemical species that are expected to show rather different water solubilities, and different effects on the hygroscopic growth factors of aerosol particles from biomass burning (Mochida and Kawamura, 2004; Biskos et al., 2006; Rissler et al., 2010; Jung et al., 2011). However, for a variety of WSOC compounds, it is not well known what the deliquescence relative humidity (DRH) of the pure compound is, which determines if it can exhibit substantial water uptake at moderate RH or not at least as long as crystallization took place at dry conditions (followed by a hydration trajectory). Some organic components that show a small solubility in pure water (i.e., these require a large volume of water to be extracted and labeled as a WSOC), may have a DRH close to $100 \% \mathrm{RH}$, which is not accessible in our hydration experiments (RH probed up to $\sim 90 \% \mathrm{RH})$. All these factors are of great importance in determining the $\mathrm{CCN}$ activity of biomass burning particles.

Previous studies have been carried out to investigate the hygroscopicity of organic-inorganic mixtures of representative model compounds from biomass burning (Cruz and Pandis, 1998, 2000; Raymond and Pandis, 2002; Abbatt et al., 2005; Henning et al., 2005; Svenningsson et al., 2006; Carrico et al., 2008; Dusek et al., 2011). For example, water uptake of surrogate mixtures containing a representative water-soluble organic fraction and inorganic compounds were studied by Svenningsson et al. (2006). They used the Zdanovski-Stokes-Robinson (ZSR) relation to compare and successfully explain the observed hygroscopic growth factors for three out of four mixtures. In addition, Carrico et al. (2008) and Dusk et al. (2011) investigated CCN activity and hygroscopic growth behavior of ambient biomass burning aerosols. However, actual biomass burning aerosols are typically much more complex in terms of composition. The hygroscopicity of biomass burning aerosols likely depends on the mixing of a diversity of organic compounds with inorganic constituents during different time periods in the field (Decesari et al., 2006).

In this work, the hygroscopic properties of relevant organic compounds from biomass burning are determined by the HTDMA technique. Using this experimental technique, we also study the influence of the organic surrogate compounds on the water uptake behavior of mixed organic-inorganic

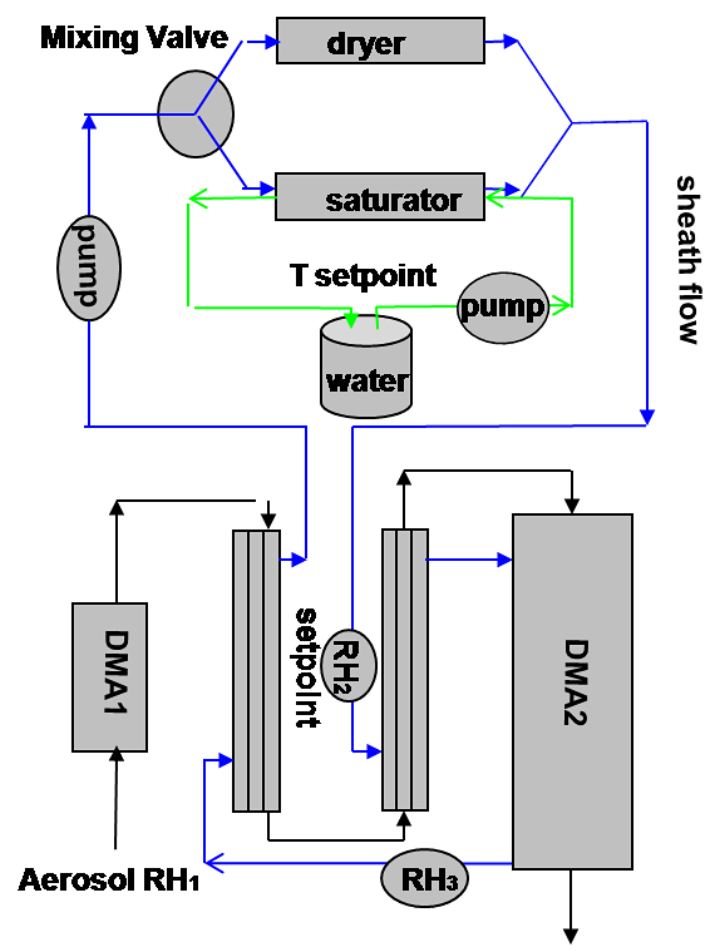

Figure 1. Schematic of the hygroscopicity tandem different mobility analyzer (HTDMA) system.

aerosols containing ammonium sulfate. Moreover, mixtures of several of the organic components with ammonium sulfate, mimicking more complex particles observed in the atmosphere, are investigated to determine the influence of organic compounds on the overall particle hygroscopicity. In addition, we use the Zdanovskii-Stokes-Robinson (ZSR) relation (Stokes and Robinson, 1966), the Extended Aerosol Inorganic Model (E-AIM) (Clegg et al., 2001; Clegg and Seinfeld, 2006; available online: http://www.aim.env.uea.ac.uk/ aim/aim.php), and the Aerosol Inorganic-Organic Mixtures Functional groups Activity Coefficients (AIOMFAC) model (Zuend et al., 2008, 2011) to predict the hygroscopic growth of mixed aerosol particles and provide comparisons to our experimental findings.

\section{Experimental and modeling methods}

\subsection{HTDMA instrument setup and experimental protocol}

A schematic of our HTDMA setup is presented in Fig. 1. The HTDMA setup is comprised of three main components: (1) the aerosol particle generation section, (2) the particles sizing and humidification system, and (3) a relative humidity control system. Polydispersed sub-micrometer particles are generated using an atomizer (MSP 1500, MSP) from bulk solutions $(0.1 \mathrm{wt} \%)$ with different mass fractions of organic and 
Table 1. Substances and their physical properties used in this work.

\begin{tabular}{|c|c|c|c|c|c|c|}
\hline $\begin{array}{l}\text { Chemical } \\
\text { compound }\end{array}$ & $\begin{array}{r}\text { Chemical } \\
\text { formula }\end{array}$ & $\begin{array}{r}\text { Molar } \\
\text { Mass } \\
{\left[\mathrm{g} \mathrm{mol}^{-1}\right]}\end{array}$ & $\begin{array}{r}\text { Density in solid } \\
\text { and liquid state } \\
{\left[\mathrm{g} \mathrm{cm}^{-3}\right]}\end{array}$ & $\begin{array}{r}\text { Solubility } \\
\mathrm{g} / 100 \mathrm{~cm}^{3} \\
\mathrm{H}_{2} \mathrm{O}\end{array}$ & $\begin{array}{r}\text { Solution } \\
\text { surface tension } \\
{\left[\mathrm{J} \mathrm{m}^{-2}\right]}\end{array}$ & Manufacture \\
\hline Ammonium sulfate & $\left(\mathrm{NH}_{4}\right)_{2} \mathrm{SO}_{4}$ & 132.140 & $1.770^{\mathrm{a}}, 1.550^{\mathrm{a}}$ & $74.400\left(\right.$ at $\left.20^{\circ} \mathrm{C}\right)$ & 0.072 & Alfa Aesar, $99.95 \%$ \\
\hline Levoglucosan & $\mathrm{C}_{6} \mathrm{H}_{10} \mathrm{O}_{5}$ & 126.100 & $1.618^{\mathrm{b}}, 1.512^{\mathrm{b}}$ & & $\begin{array}{r}0.073^{\mathrm{c}} \\
\left(0.01-10 \mathrm{mg} \mathrm{mL}^{-1}\right)\end{array}$ & Aldrich, $99 \%$ \\
\hline $\begin{array}{l}\text { 4-Hydroxybenzoic acid } \\
\text { Humic acids }\end{array}$ & $\mathrm{C}_{7} \mathrm{H}_{6} \mathrm{O}_{3}$ & $\begin{array}{r}138.100 \\
\text { NA }\end{array}$ & $\begin{array}{r}1.460,1.372^{\mathrm{d}} \\
0.800^{\mathrm{f}}\end{array}$ & $\begin{array}{r}0.675\left(\text { at } 25^{\circ} \mathrm{C}\right) \\
\mathrm{NA}\end{array}$ & $\begin{array}{r}0.070^{\mathrm{e}} \\
0.073^{\mathrm{i}}\end{array}$ & $\begin{array}{r}\text { Alfa Aesar, } 99.99 \% \\
\text { Aldrich, } 99 \%\end{array}$ \\
\hline
\end{tabular}

${ }^{a}$ Clegg and Wexler (2011a);

${ }^{\mathrm{b}}$ Lienhard et al. (2012);

c Tuckermann and Cammenga (2004);

d Jedelský et al. (2000);

e Kiss et al. (2005);

f Yates III and Wandruszka (1999).

${ }^{\mathrm{i}}$ Mikhailov et al. (2008).

inorganic species mixed with deionized water (EASY Pure ${ }^{\circledR}$ || UF ultrapure water system, resistivity $>18.2 \mathrm{M} \Omega \mathrm{cm}$ ), assuming that the compositions of the mixed aerosols remain the same as that of the solution used in the atomizer. The aerosol particles pass through three silica gel diffusion dryers (SDD) and a Nafion gas dryer (Perma Pure Inc., USA), bringing the particles to a dry state $\left(\mathrm{RH}_{1}<5 \%\right)$. The dry aerosols are subsequently charged and then enter the first differential mobility analyzer (DMA1), where a near-monodisperse distribution of particles of the desired dry diameter $\left(D_{0}\right)$ of $100 \pm 1 \mathrm{~nm}$ is selected. After size selection, aerosols are prehumidified in a Nafion conditioner tube, and they then flow into a second Nafion tube at the set relative humidity, $\mathrm{RH}_{2}$, of a growth factor measurement. The residence time of aerosol flow before entering into DMA2 is about $5 \mathrm{~s}$ in the humidification section. This residence time may be insufficient for some organic compounds to reach equilibrium at the high RH because of a very low accommodation coefficient (Kerminen, 1997; Ha and Chan, 2001; Zhang and Chan, 2000; Peng and Chan, 2001; Chan et al., 2005). For example, for aqueous particles (aqueous inner phases) coated with organic layers, $\mathrm{MgSO}_{4}$, sodium pyruvate, glutaric acid and asparagine (citation required). They need typically a longer residence time than just a seconds to reach equilibrium. Finally, the number size distributions for the humidified aerosols are measured using the second DMA (DMA2) coupled with a condensation particle counter CPC (Model 1500, MSP). These number size distributions as a result of a particular experiment are generated from the measured data (scanning DMA2) by using an inversion program that is based on a log-normal size distribution approximation (Stolzenburg and McMurry, 2008). The relative humidity of the DMA2 sheath flow, $\mathrm{RH}_{3}$, is measured using a dew point hygrometer (Michell, UK), with an uncertainty of $\pm 0.08 \% \mathrm{RH}$. To allow the aerosol to equilibrate at the specified $\mathrm{RH}$, we ensure that $\mathrm{RH}_{3}$ is equal to $\mathrm{RH}_{2}$. In addition, critical orifices were used to regulate the
Table 2. Initial dry diameter $\left(D_{\mathrm{h}, \mathrm{dry}}\right)(\mathrm{RH}<5 \%)$ and minimum mobility diameter $\left(D_{\mathrm{h}, \mathrm{min}}\right)$ in hydration $(\mathrm{h})$ mode of the HTDMA experiments.

\begin{tabular}{lll}
\hline Aerosol type & $D_{\mathrm{h}, \mathrm{dry}(\mathrm{nm})}$ & $D_{\mathrm{h}, \min (\mathrm{nm})}$ \\
\hline Ammonium sulfate & 100.6 & 99.5 \\
Levoglucosan & 99.8 & 99.6 \\
Humic acid & 100.4 & 100.3 \\
4-Hydroxybenzoic acid & 100.2 & 95.0 \\
\hline
\end{tabular}

sheath flows, which were both recirculated using closed-loop arrangements (Jokinen and Makela, 1997).

\subsection{Theory and modeling methods}

The mobility-diameter growth factor is calculated as the ratio of mobility a particle established after exposure to a set RH level (mobility-diameter after humidification) to the reference mobility of the dry aerosol particles (at $\mathrm{RH}<5 \%$ ). Hygroscopic diameter growth factors, $\mathrm{GF}(\mathrm{RH})$ are defined by $\mathrm{GF}(\mathrm{RH})=D(\mathrm{RH}) / D_{0}$, where $\mathrm{D}(\mathrm{RH})$ is the particles diameter at a specific RH and $D_{0}$ the diameter at dry conditions $(\mathrm{RH}<5 \%) ; D_{0}$ is often taken as the initial mode diameter of the aerosol $\left(D_{\mathrm{h}, \text { dry }}\right)$ at dry conditions, $\mathrm{RH}<5 \%$ selected by DMA1. In addition, following the definition of Mikhailov et al. $(2004,2008,2009)$, a reference diameter $D_{0}$ can be defined as being the minimum diameter $\left(D_{\mathrm{h}, \min }\right)$ observed while following an experimental protocol. The values of this minimum diameter and initial dry diameter of our experiments are summarized in Table 2 (for set dry RH3 below 5\% RH in the HTDMA operation) and measured hygroscopic growth factors of compounds presented in Fig. 2. In addition, hygroscopic diameter growth factors based on reference dry size minimum diameters are predicted using different thermodynamic models and mixing rules. In each model, we assume that these particles are spherical. As a 
consequence, the predicted mobility equivalent diameter is equal to the volume-equivalent diameter of a sphere.

\subsubsection{GF data fit}

An expression proposed by Dick et al. (2000) is used to present the relationship between water activity, $a_{\mathrm{w}}$ and GF (RH) for particles of individual compounds:

$\mathrm{GF}=\left[1+\left(a+b \times a_{\mathrm{w}}+c \times a_{\mathrm{w}}^{2}\right) \frac{a_{\mathrm{w}}}{1-a_{\mathrm{w}}}\right]^{\frac{1}{3}}$,

$\mathrm{RH} / 100 \%=a_{\mathrm{w}} \times K_{e}$,

$K_{e}=\exp \left\{\frac{4 \sigma_{\mathrm{sol}} M_{\mathrm{w}}}{\operatorname{RT} \rho_{\mathrm{w}} D_{\mathrm{p}}}\right\}$

Here $a_{\mathrm{w}}$ is the bulk water activity (mole fraction basis) at the composition of the solution droplet corresponding to gas phase $\mathrm{RH}$ at equilibrium with a bulk solution, $\sigma_{\text {sol }}$ is the surface tension of the solution, $M_{\mathrm{W}}$ is the molecular weight of water, $\rho_{\mathrm{W}}$ is the density of pure water at $T, R$ is the universal gas constant, $T$ is the temperature, $D_{\mathrm{p}}$ is the sphereequivalent mobility particle diameter, and $K_{e}$ is the so-called Kelvin correction factor term accounting for the droplet curvature.

The simplest assumption is that the Kelvin factor is equal to 1 (i.e., neglecting the droplet curvature effect), applicable to sufficiently large particles, however, for $100 \mathrm{~nm}$ diameter particles, ignoring the Kelvin effect at a given RH level and measured growth factor, leads to an error in the corresponding bulk solution equivalent water activity of about 1-2\% (Kreidenweis et al., 2005; Koehler et al., 2006). In this work, we have corrected all HTDMA GF data by evaluating the Kelvin term (Eq. 3) for the retrieved droplet size at a certain $\mathrm{RH}$ to obtain the corresponding water activity for comparison with models. The coefficients $a, b$, and $c$ of Eq. (1) are determined by fitting Eq. (1) to GF vs. $a_{\mathrm{w}}$ values obtained by using Eq. (2) with measured GF data at known experimental RH levels. Equation 1) is appropriate to describe continuous water uptake behavior of particles with a reference diameter at dry conditions (i.e., with $\mathrm{GF}=1.0$ at $\mathrm{RH}=0 \%$ ).

\subsubsection{GF predictions by ZSR}

Assuming that the water uptake for each of the components of mixed particles can be treated independently at a given RH, i.e., the assumption of the Zdanovskii-Stokes-Robinson mixing rule, and that the partial volumes of individual components/phases are additive, the GF of a mixture, $\mathrm{GF}_{\text {mix }}$ (RH), can be estimated from the $\mathrm{GF}_{j}$ of the pure components $j$ and their respective volume fractions, $\varepsilon_{j}$, in the mixture (Malm and Kreidenweis, 1997):

$\mathrm{GF}_{\text {mix }}=\left[\sum_{j} \varepsilon_{j}\left(\mathrm{GF}_{j}\right)^{3}\right]^{\frac{1}{3}}$.

\subsubsection{GF prediction by E-AIM}

E-AIM is a thermodynamic equilibrium model used for calculating gas/liquid/solid partitioning, widely used in the community. This model includes density predictions for aerosol systems containing inorganic and organic components in aqueous solutions. This allows for better consideration of non-ideal mixing effects on solution density, and hence particle diameter at different RH. The groupcontribution method UNIFAC (universal quasi-chemical functional group activity coefficients) (Fredenslund et al., 1975; Hansen et al., 1991), can be used within the E-AIM model to predict activity coefficients in aqueous solutions of multifunctional organic compounds Clegg et al., 2001). However, the standard UNIFAC model (Fredenslund et al., 1975; Hansen et al., 1991) is usually not appropriate for organic components in which two strongly polar groups are separated by less than four carbon atoms giving rise to intramolecular interactions, such as hydrogen bonding between certain polar groups. Some specific interaction parameters of UNIFAC were revised by Peng et al. (2001). The use of these modified UNIFAC parameters improves the prediction of the water activity of dicarboxylic acids and hydroxydi-carboxylic and hydroxy-tricarboxylic acids. These modified UNIFAC parameters can also be chosen for calculations within the E-AIM model. The use of E-AIM model for mixed organic-inorganic systems has been described in a range of papers (Hanford et al., 2008; Clegg and Seinfeld, 2006; Hanford et al., 2008; Pope et al., 2010a; Yeung and Chan, 2010).

We applied the E-AIM model to obtain the equilibrium state of aqueous mixtures and predict the GF as a function of RH. The water uptake by the organic components is estimated by choice with either the standard UNIFAC model or the modified UNIFAC model with certain interaction parameters by Peng et al. (2001), denoted UNIFAC-Peng as part of the E-AIM model. Both flavors of UNIFAC have been applied for certain systems studied in this work.

\subsubsection{GF prediction by AIOMFAC}

The AIOMFAC model by Zuend et al. $(2008,2011)$ is a thermodynamic group-contribution model designed to calculate activity coefficient covering inorganic, organic, and organic-inorganic interactions in aqueous solutions over a wide concentration range. Like the optional choice in the E-AIM model, AIOMFAC also includes a modified UNIFAC model. In addition, AIOMFAC includes long-range and middle-range molecular interaction contributions based on a semi-empirical Pitzer-type model expression to explicitly account for interactions between inorganic ions and organic functional groups (plus water) in mixed solutions. This model has been successfully applied to a variety of thermodynamic equilibrium calculations, including the consideration of liquid-liquid phase separation and the deliquescence 

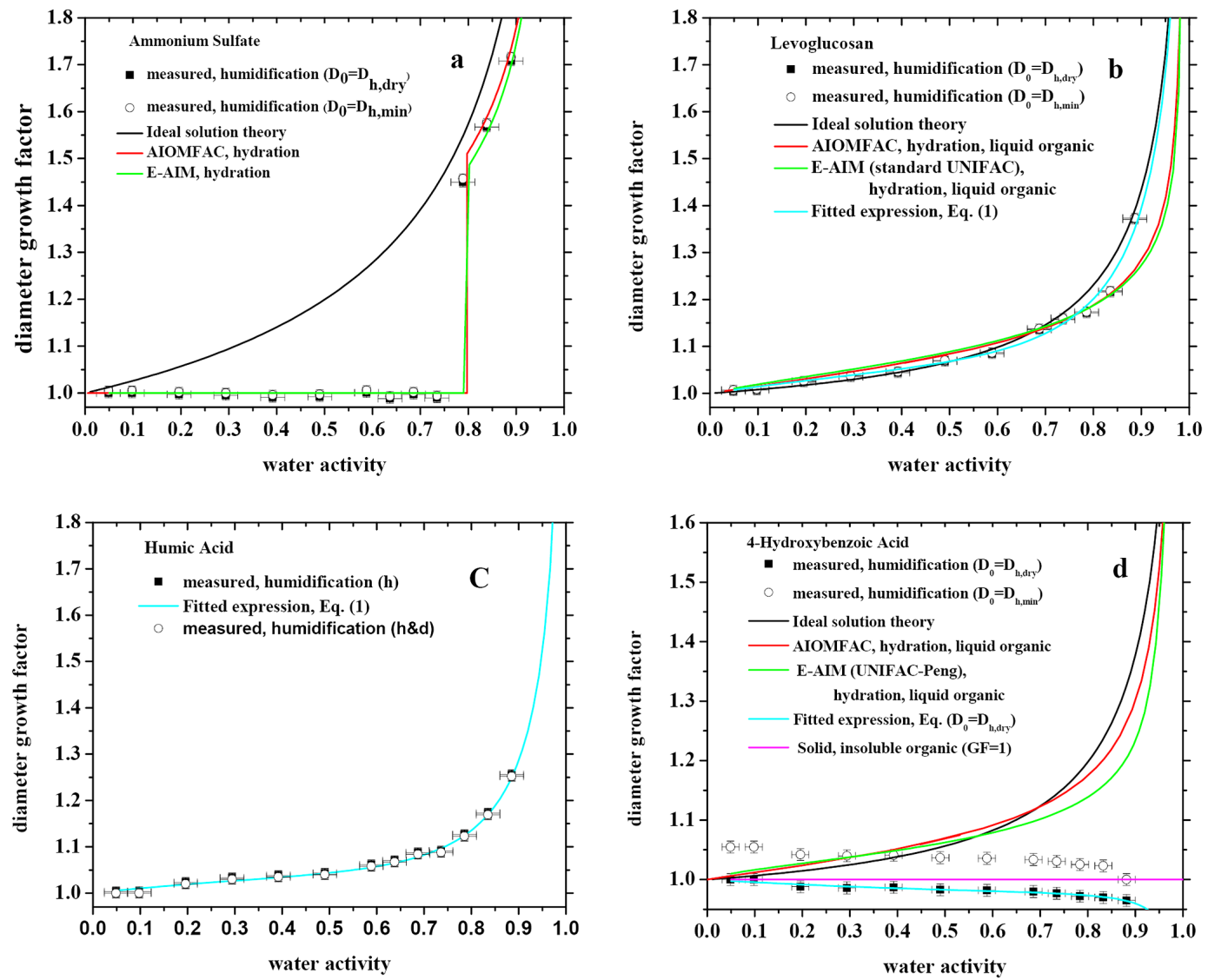

Figure 2. Hygroscopic diameter growth factor (GF) for $D_{0}$ (initial dry diameter $\mathrm{RH}<5 \%$ ) aerosol particles. The measurements, model calculations, and fitted expression Eq. (1) represent conditions of particle growth during a hydration experiment from $5 \%$ to $90 \%$ RH at 298.15 K. Measured growth factors are corrected for the Kelvin effect and are therefore shown vs. water activity. Symbols: measured GF are

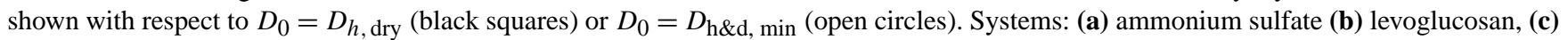
humic acid, and 4-hydroxybenzoic acid.

Table 3. Coefficients $(a, b, c)$ of the fitted growth curve parameterization to measured growth factor data using Eq. (1). Measured growth factors of $D_{0} \mathrm{~nm}$ particles used in Eq. (1) were first corrected for the Kelvin effect.

\begin{tabular}{lrrr}
\hline Chemical compounds & $a$ & $b$ & $c$ \\
\hline Levoglucosan & 0.45602 & -0.69869 & 0.44755 \\
4-Hydroxybenzoic acid $D_{0}=D_{\text {h, dry }}$ & -0.14061 & 0.22767 & -0.09526 \\
Humic acid & 0.33579 & -0.60172 & 0.40850 \\
\hline
\end{tabular}

of ammonium sulfate (e.g., Zuend et al., 2010; Song et al., 2012; Zuend and Seinfeld, 2012; Shiraiwa et al., 2013).

In this study, we use a thermodynamic equilibrium model based on AIOMFAC (Zuend and Seinfeld, 2012; Shiraiwa et al., 2013) which assumes that all components are in a liquid or amorphous (viscous) solution, potentially exhibiting liquid-liquid phase separation in a certain RH range - except for ammonium sulfate, which, as an option, is allowed to form a crystalline phase in equilibrium with the remaining solution (to represent the efflorescence and deliquescence hysteresis behavior of the inorganic salt depending on the mode of hydration/dehydration and starting $\mathrm{RH}$ in computations). Liquid-liquid phase equilibria are predicted using the algorithm of Zuend and Seinfeld (2013). However, the formation of solid (crystalline) organic phases is not generally considered at this point since in actual complex organic aerosols, the formation of crystalline organic phases is likely suppressed (Marcolli et al., 2004). Thus, in the context of this study, where solid organic phases may be present in some of the systems, the model will not be applicable - at least not to as part of the hydration branch of a humidity cycle. As an exception, we apply the model for the mixed systems 
Table 4. The chemical composition of biomass-burning model mixtures studied, given as mass percentages (wt \%).

\begin{tabular}{lllll}
\hline Mixture name & $\begin{array}{l}\text { Ammonium } \\
\text { sulfate }\end{array}$ & Levoglucosan & $\begin{array}{l}\text { 4-Hydroxybenzoic } \\
\text { acid }\end{array}$ & $\begin{array}{l}\text { Humic } \\
\text { acid }\end{array}$ \\
\hline Mix-bio-dry & $68.0 \%$ & $26.0 \%$ & $3.0 \%$ & $3.0 \%$ \\
Mix-bio-wet & $87.2 \%$ & $9.2 \%$ & $1.5 \%$ & $2.1 \%$ \\
\hline
\end{tabular}

of 4-hydroxybenzoic acid and ammonium sulfate also in a mode where the assumption is made that the organic component is solid and insoluble over the whole RH range considered (this allows for better comparison with the experimental findings). Since this thermodynamic model predicts the water content (mole fraction of water) of a mixture in equilibrium with the gas phase at a given RH level, mass growth factors can be calculated directly. However, to compute diameter growth factors, assumptions about the density of different mixture components and non-ideal mixing effects on solution density need to be made. Here we use the simplified assumption of additive component volumes, while accounting for differences between the densities of solid ammonium sulfate and dissolved aqueous ammonium sulfate. In the case of water and the organic components, the physical state is assumed to be liquid (potentially a supercooled liquid) at room temperature for the purpose of defining density values. The following density values of the pure components are used (which can be converted to specific or molar volumes): $\rho$ (water) $=0.9971 \mathrm{~g} \mathrm{~cm}^{-3}$ (Lienhard et al., 2012), $\rho$ (levoglucosan) $=1.512 \mathrm{~g} \mathrm{~cm}^{-3}$ (Lienhard et al., 2012), $\rho$ (4-hydroxybenzoic acid) $=1.3723 \mathrm{~g} \mathrm{~cm}^{-3}$ (Jedelský et al., 2000), $\rho$ (ammonium sulfate, liquid) $=1.55 \mathrm{~g} \mathrm{~cm}^{-3}$ (Clegg and Wexler, 2011b), and $\rho$ (ammonium sulfate, solid) $=1.77 \mathrm{~g} \mathrm{~cm}^{-3}$ (Clegg and Wexler, 2011b). All model calculations are performed for bulk solution properties, i.e., sufficiently large particles, where no curvature correction is necessary. For comparisons with measurements, the experimental data were corrected, as discussed in Sect. 2.2.1.

\subsubsection{Ideal solution growth factor}

The water activity of an ideal solution containing a nonvolatile, non-electrolyte component is equal to the mole fraction of water $\left(x_{\mathrm{w}}\right)$ (activity coefficients of unity). Thus, in the case of an ideal solution, we can estimate the water activity of liquid particles directly from the knowledge of water content in term of $x_{w}$. Solutions comprising electrolyte components, such as ammonium sulfate or sulfuric acid, are usually strongly deviating from an ideal solution due to substantial dissolution (dissociation) of the electrolytes and non-ideal interaction between ions, water, and organic compounds. Therefore, water activities of mixed organic-inorganic systems may substantially differ from a prediction by an ideal solution assumption (e.g., Zuend et al., 2011).
In this study, the ideal solution growth factor is used to explore its use as a simple approach to describe the hygroscopic diameter growth factor of pure components and mixtures, e.g., for ammonium sulfate and mixed particles. Since hygroscopic diameter growth factor measurements using the HTDMA are on volume basis, the ideal solution GF is calculated using mole fractions by the equation:

$\mathrm{GF}=\left[\frac{\sum_{j}\left(x_{j} M_{j} \frac{1}{\rho_{j}}\right)}{\sum_{j, j \neq w}\left(x_{j} M_{j} \frac{1}{\rho_{j}}\right)}\right]^{\frac{1}{3}}$.

Here, $x_{j}, M_{j}$, and $\rho_{j}$ are mole fraction, molar mass and mass density of component $j$, respectively. The sum in the numerator of Eq. (3) goes over all components including water, while the sum in the denominator goes over all components except for water $(j \neq w$; "dry" conditions). Note that when dissociated electrolyte components are present in the liquid mixtures, the mole fractions in Eq. (3) have to be calculated as mole fractions with respect to completely dissociated electrolytes (or an applicable degree of dissociation). Equation (3) is more likely applicable when water and the solute components are in a liquid solution, i.e., no solids present. In addition, it is assumed that the partial molar volumes of organics and water in solution are equal to those of the respective pure liquid components.

\section{Results and discussion}

\subsection{GF of single solute systems}

The hygroscopic behavior of ammonium sulfate aerosol close to room temperature is well understood and has been characterized by several groups (Gysel et al., 2002; Kreidenweis et al., 2005; Biskos et al., 2006a, b). We can use it as a reference substance to calibrate the HTDMA setup because of its well-known deliquescence point (80\% RH at $294.8 \mathrm{~K}$ ) (Onasch et al., 1999).

Figure 2a presents growth factors with respect to $D_{0}=$ $D_{h, \text { dry }}$ and $D_{0}=D_{h, \text { min }}$ ammonium sulfate particles from low to high $\mathrm{RH}$. The measured growth factor of ammonium sulfate is $1.45 \pm 0.01$ at $80 \% \mathrm{RH}$ after deliquescence. The data agree well with values measured by Gysel et al. (2002) and Wise et al. (2003). For example, the GF of AS is 1.45 at $80 \% \mathrm{RH}$ at $24.9^{\circ}$ as measured by Wise et al. (2003). In addition, the effects of particle shape/porosity restructuring 
on hygroscopic behavior of AS particles investigated are rather small (Mikhailov et al., 2004, 2008, 2009). The hygroscopic growth experiments for pure AS are also in good agreement with the prediction from the E-AIM model and the AIOMFAC model. Here, both models correctly account for the solid, crystalline state of AS in the RH range before the deliquescence at $\sim 80 \% \mathrm{RH}$ for the conditions of a hydration experiment. Slight differences between these two thermodynamic models, which both account very well for the non-ideal solution behavior of AS, are mainly due to different conversions of mass growth to diameter growth factors by the models. The E-AIM model includes a compositiondependent solution density model, while the AIOMFACbased model simply assumes volume additivity (see discussion in Sect. 3.2). However, assuming an ideal solution, without consideration of the solid state and mixing effects on solution density, its prediction for AS results in higher than measured hygroscopic growth, also for $\mathrm{RH}>80 \%$.

As shown in Fig. 2b, levoglucosan aerosol particles show continuous water uptake from low to high RH, and no deliquescence phase transition is observed, in excellent agreement with the behavior reported by Mochida and Kawamura et al. (2004) and Svenningsson et al. 2006. The measured GF at $80 \% \mathrm{RH}$ is $1.17 \pm 0.01$, which is similar to a result from the literature (Mochida and Kawamura, 2004), which report a growth factor of levoglucosan of 1.18 at $80 \% \mathrm{RH}$. Also, the measured hygroscopic growth factors are reasonably consistent with those estimated from the standard UNIFAC model within the E-AIM model, the AIOMFAC model, ideal solution theory, and the fitted expression Eq. (1). At higher RH, deviations between the different models become more significant for a good estimate of the actual GF. The measurements also suggest that levoglucosan absorbs a small amount of water even at $5 \% \mathrm{RH}$, and that it remains liquid over the full range of $\mathrm{RH}$, and potentially rather viscous at lower $\mathrm{RH}$. However, another possible explanation for slight water uptake of levoglucosan could be that nanoparticles produced by crystallization at very low RH contain volume and surface defects (porosity, polycrystalline state), which may facilitate water adsorption followed by absorption starting already at low relative humidity (Mikhailov et al., 2008, 2009). This possibility cannot be ruled out by our measurements, but the observation, which do not show a deliquescence step, would suggest that such an effect could only take place with a gradual deliquescence in the levoglucosan system. Zuend et al. (2011) discuss the case of AIOMFAC predictions for levoglucosan and its mixtures with different inorganic electrolytes. They state that the molecular structure of levoglucosan with several polar functional groups in close vicinity leads to less accurate model predictions for solutions containing this compound. The same is true for UNIFAC model predictions and is therefore a well-known limitation of these models for this particular system, explaining the observed deviations between model curves and measurements.
As can be seen from Fig. 2c, humic acid aerosol particles show a slight increase in GF from $10 \%$ RH to $70 \%$. Above $70 \% \mathrm{RH}$, the particles start to take up increasingly more water toward high RH. The effects of microscopic restructuring on the water uptake of humic acid aerosol particles are relatively the same small, comparable with those of ammonium sulfate and levoglucosan aerosol particles. These measured GF are slightly higher than the measured hygroscopic growth factors of Leonardite Standard HA by Brooks et al. (2004). For example, the measured GF at $80 \%$ is $1.13 \pm 0.01$ while Brooks et al. (2004) report a growth factor of humic acid of $1.0 \pm 0.01$ at $80 \%$ RH. However, a contrasting phenomenon was reported by Zamora and Jacobson (2013) who observed no hygroscopic growth of humic acid particles was observed over the full range of RH in their study, perhaps due to different origin and composition of the humic acid samples. Due to the lack of detailed physical and chemical information about the used humic acid, the GF of humic acid particles are only presented with a data fit based on Eq. (1). The determined fit parameters are listed in Table 2. For model calculations with E-AIM and AIOMFAC, the chemical structure or at least the type and relative abundance of functional groups needs to be known, which is not the case for the humic acid particles.

The hygroscopic growth curves for 4-hydroxybenzoic acid are presented in Fig. 2d. No hygroscopic growth (within error) was observed below $90 \% \mathrm{RH}$. Measured hygroscopic diameter growth factors with respect to $D_{h, \min }$ are above 1.0, and are close to 1.0 toward high RH (the minimum diameter was found at the highest RH measured). The main reasons for the observation of smaller particles at higher RH are likely restructuring and/or partial evaporation of particles at higher relative humidity in the hydration mode. The measured hygroscopic diameter growth factor with respect to $D_{h \text {,dry }}$ show of course the same slight decrease in particles diameter with increasing RH. The $D_{h \text {,dry }}$ definition of the reference diameter leads to GF smaller than 1.0 at higher $\mathrm{RH}$, which is consistent with previous experiments by another group (Mochida and Kawamura, 2004). The reasons for the decrease in particle diameter are not fully understood, but the same behavior is reported by Shi et al. (2012) for particles consisting of ammonium sulfate + benzoic acid. On the basis of transmission electron microscopy (TEM) image analysis, they attribute the diameter decrease to the microscopic restructuring of solid particles with increasing $\mathrm{RH}$, which may affect the particle mobility diameter. Therefore, a similar effect could be responsible for the observations from our experiments. Another potential reason for a decrease in apparent diameter could be the partial evaporation of semivolatile organics from the aerosol particles in the HTDMA (here: 4-hydroxybenzoic acid, pure liquid vapor pressure $p^{0, \mathrm{~L}}=8.11 \times 10^{-4} \mathrm{~Pa}$ at $298.15 \mathrm{~K}$, Booth et al. 2012), an effect that is also known for certain volatile inorganic particles (e.g., $\mathrm{NH}_{4} \mathrm{NO}_{3}$ ) (Lightstone et al., 2000; Hersey et al., 2013). In order to probe hysteresis effects of 4-hydroxybenzoic acid during hydration and dehydration 
processing of the aerosol, another experiment was conducted for 4-hydroxybenzoic acid. First, the 4-hydroxybenzoic acid aerosol particles were passed through a water supersaturation humidifier (RH of above $100 \%$ ), followed by drying to the different RH setpoints ( $90 \%$ to $5 \% \mathrm{RH}$ ). No obvious diameter changes other than potential restructuring effects were observed in this experiment. A possible reason is that the particles deliquesce in the oversaturation humidifier, but that their efflorescence occurs above $90 \% \mathrm{RH}$, likely even above $97 \%$ RH by their efflorescence (Mochida and Kawamura, 2004). A second possible issue could be that the residence time in the humidifier section $(\sim 5 \mathrm{~s})$ of our HTDMA setup is too short for $100 \mathrm{~nm}$ 4-hydroxybenzoic acid particle to fully deliquesce. Our observations of this very limited solubility of 4-hydroxybenzoic acid, and hence, a high DRH are in agreement with the experimental data of Mochida and Kawamura (2004) for this system. Obviously, the observed results are different from the GF curves predicted by the ideal solution theory, the AIOMFAC model, and the UNIFAC-Peng (within E-AIM) model. For these predictions starting with particles at $0 \% \mathrm{RH}$, the applied models assume that the organic component is present in the liquid state and that solid organic phases are not present. However, the experimental data indicate that 4-hydroxybenzoic acid is solid and remains solid in the range from $5 \%$ to $90 \% \mathrm{RH}$ for a hydration experiment. Hence, the shown model predictions clearly deviate from the measurements due to the unfavorable assumption of a liquid solution and not because of a general limitation of the models for describing growth factors of the aqueous 4hydroxybenzoic acid. Would the models account for a solid organic phases, the predicted GF would be 1.0 throughout the shown experimental $\mathrm{RH}$ range with deliquescence of the organic crystal expected to occur at an $\mathrm{RH}$ value greater than $90 \%$. Indeed, the model curves may well capture the water uptake/loss behavior prior to crystallization for the case of a dehydration experiment starting at very high $\mathrm{RH}(\sim 100 \%)$ with liquid particles becoming supersaturated, metastable solution as RH is decreased below the deliquescence point).

\subsection{Mixed systems: ammonium sulfate + levoglucosan}

The measured water uptake by $100 \mathrm{~nm}$ particles consisting of different mixtures of ammonium sulfate + levoglucosan with dry mass ratios of $3: 1,1: 1$, and $3: 1$, shown in Fig. 3, present a reduction in the GF at $\mathrm{RH}>80 \%$ with increasing levoglucosan mass fraction and therefore decreasing AS content. For example, the growth factors are 1.30, 1.30, and 1.28 at $80 \% \mathrm{RH}$, respectively, relative to the GF of 1.45 of pure AS particles at $80 \% \mathrm{RH}$. There is a clear shift in the full deliquescence of $\mathrm{AS}$ at $\mathrm{RH}=\sim 80 \% \mathrm{RH}$ to lower $\mathrm{RH}$ with increasing levoglucosan mass fraction, which indicates the levoglucosan aerosol particles have significant effect on the deliquescence of ammonium sulfate. And with increasing levoglucosan mass fraction, the smoothing of hygroscopic growth factor curves is obvious. This phenomenon was ob- served for mixtures of ammonium sulfate and succinic acid, malonic acid, monomethylaminium sulfate (MMAS), and dimethylaminium sulfate (DMAS) by previous studies (e.g., Zardini et al., 2008; Hämeri et al., 2002; Qiu and Zhang, 2013). For example, Qiu and Zhang (2013) observed that particles consisting of $10 \mathrm{wt} \%$ MMAS ( or $10 \mathrm{wt} \%$ DMAS) and ammonium sulfate exhibit a moderate growth by water uptake in the $\mathrm{RH}$ range of 40-70\% $\mathrm{RH}$. In addition, the hygroscopicity of internal mixtures of ammonium sulfate aerosol and levoglucosan with core-shell and well-mixed structures were experimentally studied by Maskey et al. (2014) using the HTDMA technique. They show that the GF of the wellmixed particles was higher than that of the core-shell particles with the same organic fraction volume.

The experimental hygroscopic growth results for AS + levoglucosan mixtures are compared with four model predictions. The E-AIM model with standard UNIFAC is in relatively good agreement with the measured hygroscopic growth factors, but slightly overestimates the water uptake at $\mathrm{RH}<\sim 70 \%$. Especially in the case of the $1: 1$ mixtures of AS: levoglucosan (by mass), the E-AIM model includes a composition dependent solution density model, (i.e., solution density depends on water content and therefore $\mathrm{RH}$ ), while the AIOMFAC-based model does not include such a sophisticated treatment. The AIOMFAC model assumes linear additivity of pure component liquid or solid volumes/density to estimate the droplet diameter at a given RH. A possible reason for small differences between the model predictions is that E-AIM model provides droplet volume output based on density predictions of the aqueous system at different compositions (Clegg and Wexler, 2011a, b), while the other two models use a simpler volume additivity approach. We attribute a small effect on predicted GF curves due to different density treatment in E-AIM and the AIOMFAC-based model based on a comparison of E-AIM and AIOMFAC-based predicted mass growth factors and diameter growth factors for pure ammonium sulfate shown in Fig. 4. Note that for this model comparison (Fig. 4) no specific particle size is assumed, i.e., these are model calculations for bulk system conditions without the necessity of a correction factor accounting for droplet curvature. Deviations in predicted diameter growth factors related to the different solution density models used are therefore visualized by the comparison of the two model predictions, especially for water activities above deliquescence of ammonium sulfate, where the predicted mass growth factors agree very well. Figure 4 illustrates that the two different thermodynamic models can yield different predictions of diameter growth factors because of two reasons: (i) differences in predicted activity coefficients for a given mixture composition, which is seen from deviations between the models in Fig. 4a (mass growth factors vs. water activity) particularly for $a_{\mathrm{w}}<\sim 0.6$ and/or (ii) due to a different solution density model used, as seen from a comparison of panels (a) and (b) of Fig. 4 for $a_{\mathrm{w}}>\sim 0.6$. Based on this comparison, slight differences between E-AIM and AIOMFAC 

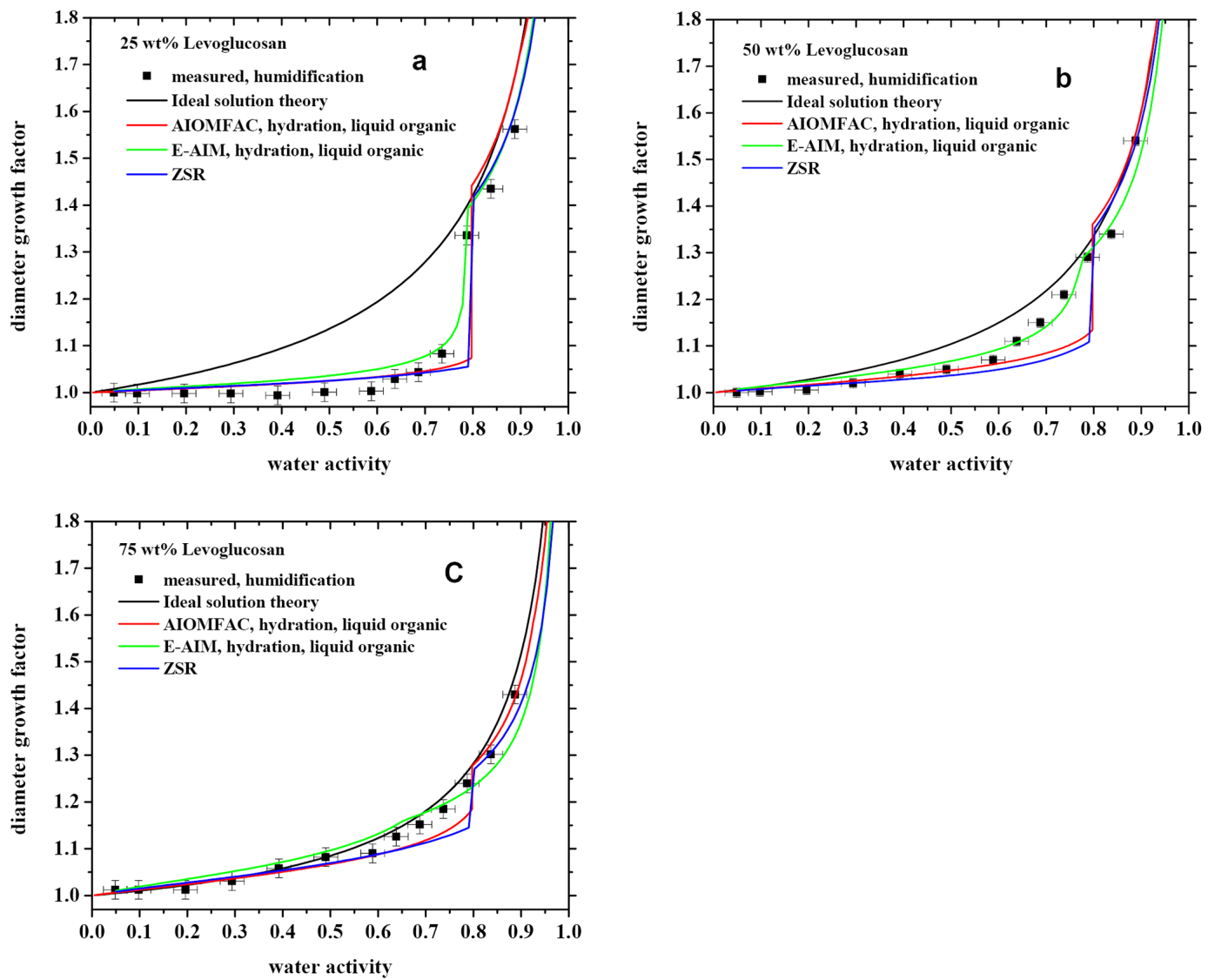

Figure 3. Hygroscopic growth factors of aerosol particles containing mixtures of levoglucosan with ammonium sulfate at three different dry state mass fractions. The measurements and model calculations represent the particle growth during a hydration experiment from $5 \%$ to $90 \%$ $\mathrm{RH}$ at $298.15 \mathrm{~K}$. Measured growth factors are corrected for the Kelvin effect and are therefore shown vs. water activity. Mass ratio of AS: Levoglucosan: (a) $3: 1$, (b) $1: 1$, (c) $3: 1$.

diameter growth factor predictions are explained by the use of two different approaches for the description of solution density (and therefore volume). In addition, for the levoglucosan + AS mixtures, the AIOMFAC-based model predicts a liquid-liquid phase separation between $80 \%$ and $\sim 90 \%$ RH for the hydration conditions. The E-AIM model does not predict a phase separation and estimates a higher miscibility between the inorganic and organic components, which seems to be in better agreement with the experimental data. This is the major reason for the differences between the two model predictions regarding the diameter growth factors above AS deliquescence in case of the levoglucosan + AS system. In addition, the E-AIM model predicts a slightly higher mutual solubility of AS and levoglucosan at RH $<80 \%$ in comparison to AIOMFAC, which leads to more dissolution of AS and associated with that, to a large water uptake at RH below full deliquescence. Regarding the ideal solution curve without consideration of a solid AS phase, the ideal curve agrees better with the measured $\mathrm{GF}_{s}$ with increasing mass fraction of levoglucosan, which is a consequence of a reduced effect and less abrupt deliquescence transition of ammonium sul- fate in the mixtures with higher levoglucosan mass fraction. The ZSR model is based on hygroscopic growth factors of ammonium sulfate and levoglucosan derived from E-AIM predictions for AS and the fitted GF curve (Eq. 1) for levoglucosan. At RH above $80 \%$, the ZSR model is in relatively good agreement with the measured particle hygroscopicities when accounting for measurement error. However, due to the nature of the classical ZSR model used, the mutual solubility of $\mathrm{AS}$ in aqueous levoglucosan solution at $\mathrm{RH}<80 \%$ below full AS deliquescence is not considered, i.e., the water uptake of organic and inorganic components is treated separately and no dissolution effects are accounted for. At those lower RH conditions, this leads to the largest deviations from experimental data for the ZSR predictions in comparison to the two other models.

\subsection{Mixed systems: ammonium sulfate + humic acid}

Hygroscopic behavior of $100 \mathrm{~nm}$ particles containing ammonium sulfate + humic acid with dry mass ratios of $3: 1,1: 1$, $3: 1$, shown in Fig. 5, present a reduction in GF at $\mathrm{RH}>80 \%$ 

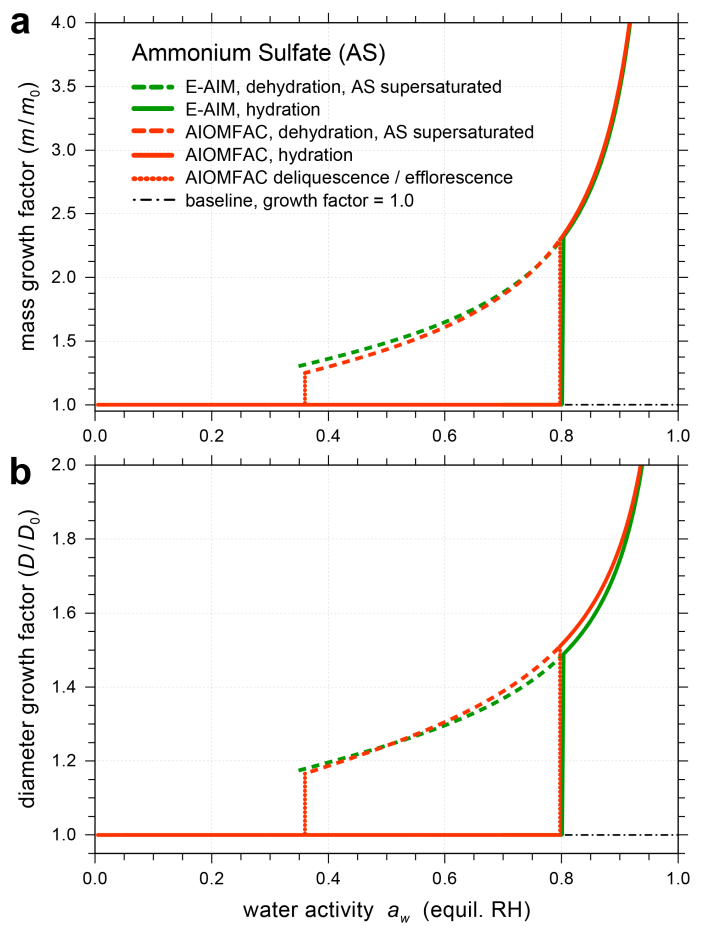

Figure 4. Comparison of E-AIM and AIOMFAC-based mass growth factors (a) and growth diameter growth factors (b) for the binary ammonium sulfate + water system at $298.15 \mathrm{~K}$.

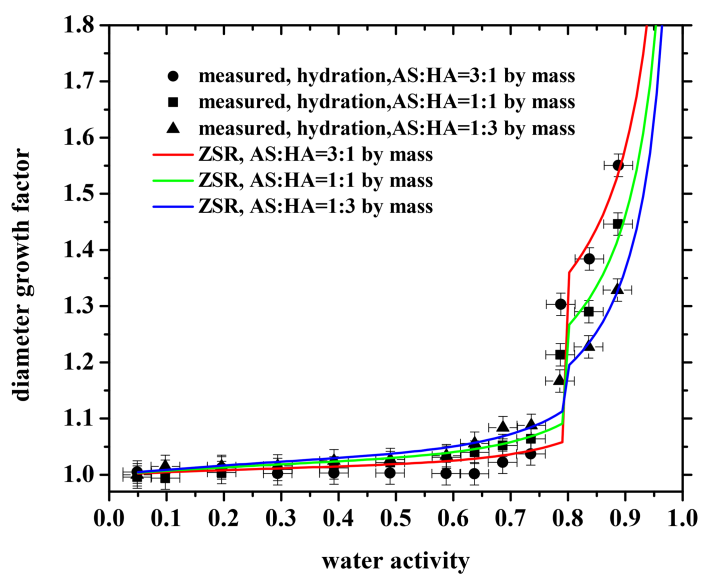

Figure 5. Hygroscopic growth factors of aerosol particles containing mixtures of humic acid (HA) and ammonium sulfate at three different dry state mass ratios. The measurements and ZSR model calculations represent the particle growth during hydration experiments from $5 \%$ to $90 \% \mathrm{RH}$ at $298.15 \mathrm{~K}$. Measured growth factors are corrected for the Kelvin effect and are therefore shown vs. water activity

with increasing mass fraction of HA (decreasing AS content). For instance, the measured growth factors are 1.30, 1.21 , and 1.18 at $80 \% \mathrm{RH}$ after full AS deliquescence for the particles containing $25 \mathrm{wt} \%, 50 \mathrm{wt} \%$ and $75 \mathrm{wt} \% \mathrm{HA}$ (dry composition) compared to a growth factor of 1.45 for pure, deliquesced AS particles at $80 \%$ RH. In addition, the HA has a lower hygroscopicity which leads the mixed particles to take up a smaller amount of water before the complete deliquescence of AS. Based on a ZSR relation assumption of (approximate) additivity of water uptake by the different mixture components according to their individual hygroscopicity, the observed reduction in GF is expected for the mixed systems. It is expected because of the lower mass fraction of the most hygroscopic component (ammonium sulfate) in these mixed systems in comparison to pure ammonium sulfate particles of the same dry size. Thus, the observed reduction in GF does not indicate a dramatic suppression of ammonium sulfate hygroscopicity by the organic components. However, present molecular interactions among organic components and dissolved ammonium sulfate may slightly affect the hygroscopicities of the individual components in comparison to pure component hygroscopicities. A similar tendency had been observed by Brooks et al. (2004) for mixtures containing HA and AS, which exhibit a size growth prior to $80 \% \mathrm{RH}$. Hygroscopic growth factors referring to the water uptake contribution by HA in the ZSR relation are obtained from the fitted growth curve of pure HA particles (Eq. 1). As for the humic acid + AS system, E-AIM predictions of the growth factors of pure AS are used in the ZSR relation here. The resulting ZSR prediction agrees relatively well with the measured hygroscopic growth of the different mixtures. Also qualitatively, when comparing the three mixtures, the ZSR prediction reproduces the lower GF of the 3:1 AS:HA particles at $\mathrm{RH}<80 \%$ least amount of HA and then by contrast the higher GF for RH $>80 \%$ due to a large water uptake contribution from AS after deliquescence. Model predictions using the E-AIM and AIOMFAC could not be performed for this system because of the lack of knowledge about the actual molecular structure of the humic acid samples used.

\subsection{Mixed systems: ammonium sulfate + 4-hydroxybenzoic acid}

Figure 6 shows the measurement and model predictions for particles consisting of ammonium sulfate +4 hydroxybenzoic acid with dry mass ratios of $3: 1,1: 1$, $3: 1$. A GF reduction from panels (a) to (c) at high relative humidity is mainly due to an increasing mass fraction of 4-hydroxybenzoic acid. For example, the measured growth factors are $1.31,1.26$, and 1.10 at $80 \% \mathrm{RH}$ after full AS deliquescence for the particles containing $25 \mathrm{wt} \%$, $50 \mathrm{wt} \%$, and $75 \mathrm{wt} \%$ 4-hydroxybenzoic acid (dry mass percentages), respectively. Hygroscopic behavior of mixed 4hydroxybenzoic acid-AS particles is found to be essentially unaffected by the presence of 4-hydroxybenzoic acid. 4hydroxybenzoic acid aerosol particles have no influence on the deliquescence point of ammonium sulfate given their low water solubility. A similar behavior was observed for mixtures of ammonium sulfate and organics containing glutaric, pinonic acid, and phthalic acid with relatively low 

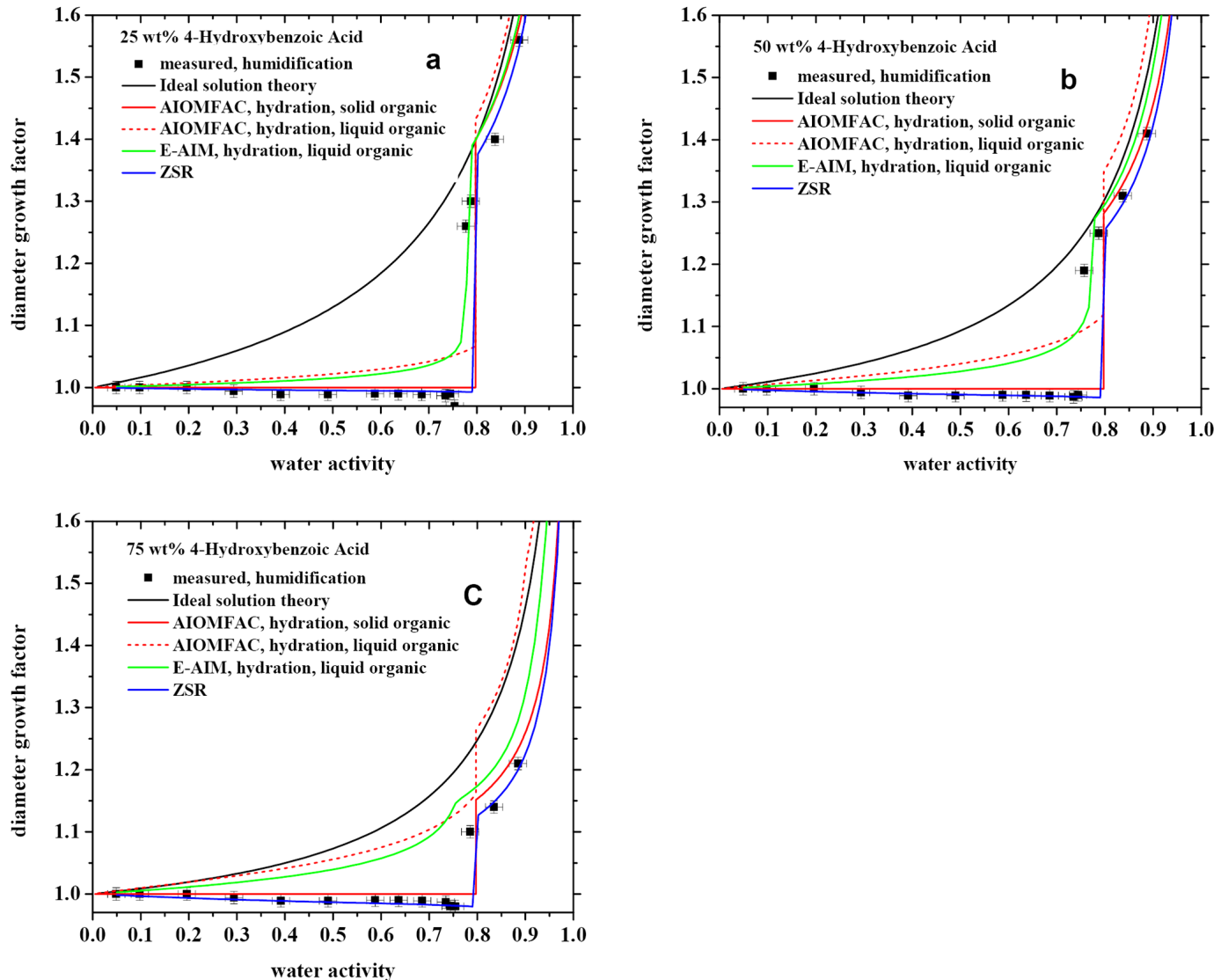

Figure 6. Hygroscopic growth factors of aerosol particles containing mixtures of 4-hydroxybenzoic acid with ammonium sulfate at three different dry mass ratios. The measurements and model calculations represent particle growth during hydration experiment from $5 \%$ to $90 \% \mathrm{RH}$ at $298.15 \mathrm{~K}$. Measured growth factors are corrected for the Kelvin effect and are therefore shown vs. water activity. Mass ratio of AS:4-Hydroxybenzoic acid: (a) $3: 1$, (b) $1: 1$, (c) $3: 1$.
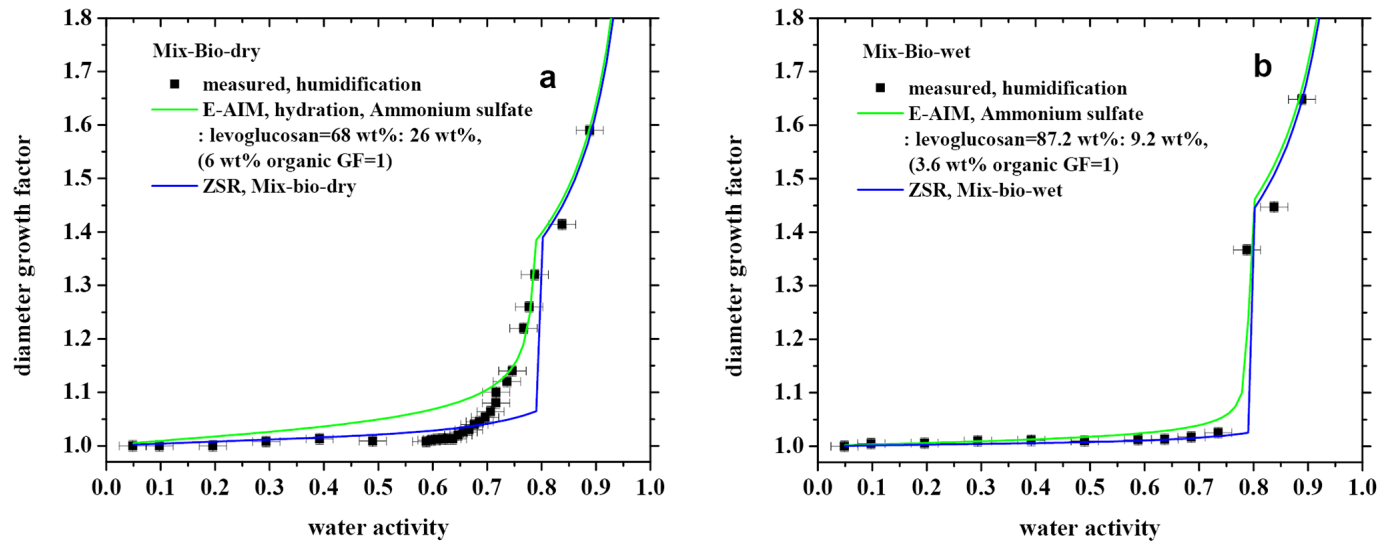

Figure 7. Hygroscopic growth factors of $100 \mathrm{~nm}$ (dry diameter) particles consisting of mixtures of organic surrogate compounds with ammonium sulfate representing particles of (a) dry and (b) wet seasonal periods in the Amazon. The measurements and model calculations describe the particle growth during hydration experiments from $5 \%$ to $90 \% \mathrm{RH}$ at $298.15 \mathrm{~K}$ systems. Measured growth factors are corrected for the Kelvin effect and are therefore shown vs. water activity. 
water solubility by Cruz and Pandis (2000) and Hameri et al. (2002). However, the GF of such particles differ from pure AS particles due to the different basis of normalization, since the dry diameter includes an insoluble organic phase for the same particles class. The ZSR relation agrees very well with the measured hygroscopic growth for mixed particles within measurement error. A reason for this results is the use of the fitted hygroscopic growth factors for 4-hydroxybenzoic acid as input for the ZSR relation (Eq. 2). For the case of particles containing AS and 4-hydroxybenzoic acid, the ideal solution curves show a large deviation from measured GFs, partly because of the solid organic phase, but it is also obvious that such mixtures deviate from ideal behavior. As in the case of the binary 4-hydroxybenzoic acid + water system (Fig. 2d), for the mixed systems with ammonium sulfate (Fig. 6), EAIM model predictions are referring to a system where the organic component remains liquid at all RH, i.e., without consideration of a solid organic phase that is most likely present during these hydration experiments. However, the crystallization and dissolution of ammonium sulfate is considered by the two thermodynamic models. Hence, the systematic offset observed when comparing model results and measurements in Fig. 6 is mainly due to incorrect model assumptions for these organic-inorganic mixtures. In the case of the AIOMFAC model prediction, a solid organic phase is assumed, i.e., it is assumed that the organic growth factor contribution GF (4-hydroxybenzoic acid) $=1.0$ for the whole RH range. The resulting particle growth prediction is still a bit higher than the measured hygroscopic particle growths above $80 \% \mathrm{RH}$. This is largely explained by the fact that the measurements indicate $\mathrm{GF}<1.0$ at $\mathrm{RH} \approx 80 \%$ and above, potentially due to particles morphology effects, which then presents a systematic offset between measurements and model prediction. Microscopical particle morphology restructuring and associated size changes of solid particles at moderate to high RH levels have been found in other experiments too. An interesting, yet contrasting phenomenon was observed by Sjogren et al. (2007). They investigated different mixtures of ammonium sulfate + adipic acid in the RH range from $\sim 5 \%$ to $\sim 95 \%$ using HTDMA instruments and an electrodynamic balance (EDB). In addition, Sjogren et al. (2007) studied the morphology of samples of their mixed aerosols containing solid (insoluble) adipic acid using scanning electron microscopy (SEM). Growth factors indicating significant water uptake at RH below the full deliquescence of AS and systematic deviations from ZSR predictions observed are explained by Sjogren et al. (2007) as a result of morphological effects, including an inverse Kelvin effect, leading to enhanced particle growth factors due to water uptake into cracks, veins and pores of polycrystalline solids. In contrast, our observations indicate a shrinking of 4hydroxybenzoic acid containing particles with increasing $\mathrm{RH}$ or at least a decrease of their mobility-equivalent diameters.

\subsection{Mixtures of biomass burning organic surrogate compounds with ammonium sulfate}

Mixtures compounds consisting of levoglucosan, humic acid, and 4-hydroxybenzoic acid, representing WSOC chemical composition for different seasonal periods in the Amazon region, based on the chemical characterization of both individual compounds analysis and functional group analysis deployed during the field experiment by Decesari et al. (2006) and Rissler et al. (2006). Also, the mixtures present quantitatively the average chemical structure of WSOC and can be used as surrogates in microphysical models involving organic aerosol particles over tropical areas affected by biomass burning (Andreae et al., 2002; Artaxo et al., 2002; Zhu et al., 2002; Rissler et al., 2006; Decesari et al., 2006). Therefore, with the organic surrogate compounds (levoglucosan, 4-hydroxybenzoic acid, and humic acid) as example of neutral compounds, mono/di-carboxylic acids, and polyacids, respectively, it is of interest to study the interaction of water with mixed ammonium sulfate-organics particles from these main organic compound classes. The effects of such organic surrogate compounds on the hygroscopic behavior of mixed organic-inorganic particles containing also ammonium sulfate are measured and discussed in following. We use the relative abundances of the three model compound classes based on the chemical composition analysis of atmospheric particles reported by Decesari et al. (2006). The chemical compositions of two distinct mixtures are given in Table 2. Mixbio-dry and mix-bio-wet are compositions typical of biomass burning aerosols in the two different seasons (dry and wet) in the Amazon basin near Rondônia, Brazil (Decesari et al., 2006).

\subsubsection{Water uptake of mix-bio-dry and mix-bio-wet particles}

The hygroscopic behavior of mix-bio-dry particles in terms of GF is presented in Fig. 7a. Mixtures of organic surrogate compounds and AS in these dry season model particles do not show any growth below $65 \%$ RH. However, mix-bio-dry particles begin to take up water at $65 \% \mathrm{RH}$ and show steep growth between $75 \%$ and $80 \%$ RH where the partial deliquescence of AS contributes increasingly to the water uptake and, hence, the overall growth factor. Similar water uptake behavior prior to full AS deliquescence has been reported by Zardini et al. (2008) and Wu et al. (2011) for different organic + ammonium sulfate mixed aerosol systems. The E-AIM model prediction for mixtures consisting of ammonium sulfate + levoglucosan with a comparable dry mass percentage ratio of $68 \mathrm{wt} \%: 26 \mathrm{wt} \%$ is in relatively good agreement with the measured growth factors above $75 \% \mathrm{RH}$, this reveals that levoglucosan, as part of the mixture of organic biomass burning organic surrogate compounds, largely contributes to the water uptake of mixtures containing organic surrogate compounds and ammonium sulfate before 
the deliquescence of AS. The ZSR model curve is calculated on the basis of the growth factors of the pure components: for AS using E-AIM, for levoglucosan, 4-hydroxybenzoic acid and humic acid using the fitted expression (Eq. 1). The ZSR prediction tends to agree well with the water uptake investigated at RH above $80 \% \mathrm{RH}$, while large deviations are found for the range between $0 \%$ and $80 \% \mathrm{RH}$, for similar reasons as discussed for the AS + levoglucosan systems (Fig. 3 and related text).

The hygroscopic behavior of mix-bio-wet particles is shown in Fig. 7b. In contrast to mix-bio-dry particles, mixbio-wet aerosols show little water uptake below $80 \%$ RH. This result is expected given the lower mass fraction of hygroscopic organics (e.g., only $9.2 \mathrm{wt} \%$ levoglucosan) in the mix-bio-wet particles. The observed hygroscopic behavior of mixed organic-inorganic aerosols of other HTDMA studies on biomass burning aerosols published in the literature, e.g, Wu et al. (2011), cannot be compared directly to our measurements, because the samples and organic : inorganic rations are different. However, the work by Wu et al. (2011) shows that other mixtures containing AS and organic acids found in biomass burning aerosol from Brazil, show significant water uptake at relative humidities below $80 \%$, similar to our mix-bio-dry case. In addition, the E-AIM model prediction for mixtures consisting of AS and levoglucosan by mass percentage ratio of $87 \mathrm{wt} \%: 9.2 \mathrm{wt} \%$ is in good agreement with the measured growth curve, which indicates that levoglucosan mainly contributes to the hygroscopic behavior of the organic aerosol fraction of the mixtures consisting of biomass burning model organics and AS. Also, due to the limited water uptake prior to AS deliquescence in the mixbio-wet case, the ZSR prediction results in a good description of the measured growth curve.

To summarize, the hygroscopic growth factor of mixed organic + ammonium sulfate particles is affected by the presence and relative composition of organic surrogate compounds from biomass burning. For example, the growth factors during humidification of mixed particles composed of model organics and AS at $80 \% \mathrm{RH}$ are 1.35 for representative dry season aerosols and 1.37 for wet season aerosols. These growth factors are lower than the GF of 1.45 for pure AS particles, which is of course expected given the lower hygroscopicity of the organic components and the general finding that water uptake contributions according to Eq. (2) usually describes a mixture's GF quite well. The measured GF values of our biomass burning model systems are similar to the ones reported by Jung et al. (2011) for biomass burning aerosols sampled in Ulaanbaatar, Mongolia, for which the GF were found to be between 1.30 and 1.35 at $80 \% \mathrm{RH}$ during hydration. Effects of organic surrogate compounds on the deliquescence behavior of AS are found with increasing mass fraction of hygroscopic organic surrogate compounds, particularly levoglucosan, from aerosol mixtures representing the wet and dry seasons in the Amazon basin. In the case of dry-period aerosols with an enhanced mass fraction of or- ganic surrogate compounds, a smoothing of the hygroscopic growth curve is observed, likely due to the continuous water uptake by levoglucosan and partial dissolution and additional water uptake by ammonium sulfate. This result is similar to the observed behavior in simple, binary mixtures of levoglucosan + AS, suggesting that 4-hydroxybenzoic acid and HA show little to no effect on the hygroscopic behavior of mixed particles during a hydration experiment starting at dry conditions.

\section{Conclusions}

According to field studies reported in the literature, aerosol particles from biomass burning events always contain a variety of inorganic and organic compounds. Different compositions of these aerosol particles have a significant influence on their physicochemical properties, in particular hygroscopic behavior. Differences regarding aerosol number concentration and particle composition were observed for the dry and wet seasons in the Amazon and other regions (Artaxo et al., 2002; Decesari et al., 2006; Rissler et al., 2006). In this work, we focused on three organic compounds (levoglucosan, 4hydroxybenzoic acid, and humic acid) to represent common compound classes from biomass burning. These organics are also representative of three different water uptake characteristics. Hygroscopic growth measurement for the twocomponent organic + AS particles show that certain organic compounds can have an important influence on the overall particle diameter growth factor and the partial deliquescence of AS, e.g., mixtures of levoglucosan with AS. With increasing mass fraction of levoglucosan, a clear shift of the onset of AS deliquescence to lower RH is occurring, which also leads to an overall more smooth looking hygroscopic growth factor curve. In contrast, 4-hydroxybenzoic acid and humic acid show no obvious effect on the deliquescence RH of AS. Also, due to the limited solubility of these two organic compounds, the hygroscopic growth factors at RH below $95 \%$, as measured, are reduced relative to that of pure AS particles.

Mixtures of organic surrogate compounds with AS, representing atmospheric aerosols from biomass burning, were made with chemical compositions determined on the basis of different organic and inorganic component fractions observed for the dry and the wet period in the Amazon basin. The most striking difference in measured hygroscopic growth curves comparing the two seasons is due to presence of different amounts of levoglucosan as surrogate compound, implying that highly oxidized organic compounds like levoglucosan may play an important role in controlling the hygroscopic behavior of atmospheric particles at RH below the full deliquescence of inorganic salts, such as AS. Therefore, a main advantage of using organic surrogate compounds representing the complex WSOC fraction of biomass burning aerosol, is their use for laboratory experiments and associated evaluation and improvement of thermodynamic mixing 
models and parameterization for the predictions of hygroscopic behavior and CCN activity in atmospheric models.

This work focuses on the water uptake and deliquescence behavior of organic compounds from biomass burning sources and their influence on the water uptake of mixed organic-ammonium-sulfate aerosol particles. Ambient biomass burning aerosol particles may undergo humidity cycles depending on the RH history of an air parcel. $\mathrm{Hu}-$ midity cycles may possibly lead to solid-liquid phase transition hysteresis with distinct deliquescence and efflorescence behavior of the organic components and organic-inorganic mixtures. Associated changes of aerosol hygroscopicity of mixed particles similar to the multi-component system studies in this work will be a topic of studies in the future.

Acknowledgements. This project was supported by the Strategic Priority Research Program (B) of the Chinese Academy of Sciences (Grant No. XDB05010400), National Basic Research Program of China (973 Program, No. 2011CB403401) of Ministry of Science and Technology of China, and the National Natural Science Foundation of China (Contract No. 41173112, 41105085, 41227805). We would also like to thank $\mathrm{Z}$. J. Wu for suggestions on hygroscopic growth factors of data fit.

Edited by: V. F. McNeill

\section{References}

Abbatt, J. P. D., Broekhuizen, K., and Kumal, P. P.: Cloud condensation nucleus activity of internally mixed ammonium sulfate/organic acid aerosol particles, Atmos. Environ., 39, 47674778, doi:10.1016/j.atmosenv.2005.04.029, 2005.

Agarwal, S., Aggarwal, S. G., Okuzawa, K., and Kawamura, K.: Size distributions of dicarboxylic acids, ketoacids, $\alpha$ dicarbonyls, sugars, WSOC, OC, EC and inorganic ions in atmospheric particles over Northern Japan: implication for long-range transport of Siberian biomass burning and East Asian polluted aerosols, Atmos. Chem. Phys., 10, 5839-5858, doi:10.5194/acp10-5839-2010, 2010.

Andreae, M. O., Artaxo, P., Brandao, C., Carswell, F. E., Ciccioli, P., da Costa, A. L., Culf, A. D., Esteves, J. L., Gash, J. H. C., Grace, J., Kabat, P., Lelieveld, J., Malhi, Y., Manzi, A. O., Meixner, F. X., Nobre, A. D., Nobre, C., Ruivo, M., Silva-Dias, M. A., Stefani, P., Valentini, R., von Jouanne, J., and Waterloo, M. J.: Biogeochemical cycling of carbon, water, energy, trace gases, and aerosols in Amazonia: The LBAEUSTACH experiments, J. Geophys. Res.-Atmos., 107, 8066, doi:10.1029/2001JD000524, 2002.

Artaxo, P., Martins, J. V., Yamasoe, M. A., Procopio, A. S., Pauliquevis, T. M., Andreae, M. O., Guyon, P., Gatti, L. V., and Leal, A. M. C.: Physical and chemical properties of aerosols in the wet and dry seasons in Rondonia, Amazonia, J. Geophys. Res.-Atmos., 107, 8081. doi:10.1029/2001jd000666, 2002.

Biskos, G., Paulsen, D., Russell, L. M., Buseck, P. R., and Martin, S. T.: Prompt deliquescence and efflorescence of aerosol nanopar- ticles, Atmos. Chem. Phys., 6, 4633-4642, doi:10.5194/acp-64633-2006, 2006a.

Biskos, G., Russell, L. M., Buseck, P. R., and Martin, S. T.: Nanosize effect on the hygroscopic growth factor of aerosol particles, Geophys. Res. Lett., 33, L07801, doi:10.1029/2005GL025199, 2006b.

Brooks, S. D., DeMott, P. J., and Kreidenweis, S. M.: Water uptake by particles containing humic materials and mixtures of humic materials with ammonium sulfate, Atmos. Environ., 38, 18591868, doi:10.1016/j.atmosenv.2004.01.009, 2004.

Carrico, C. M., Petters, M. D., Kreidenweis, S. M., Collett, J. L., Engling, G., and Malm, W. C.: Aerosol hygroscopicity and cloud droplet activation of extracts of filters from biomass burning experiments, J. Geophys. Res., 113, 113, D08206, doi:10.1029/2007jd009274, 2008.

Chan, M. N. and Chan, C. K.: Hygroscopic properties of two model humic-like substances and their mixtures with inorganics of atmospheric importance, Environ. Sci. Technol., 37, 5109-5115, doi:10.1021/es034272o, 2003.

Chan, M. N., Choi, M. Y., Ng, N. L., and Chan, C. K.: Hygroscopicity of water-soluble organic compounds in atmospheric aerosols: Amino acids and biomass burning derived organic species, Environ. Sci. Technol., 39, 1555-1562, doi:10.1021/es0495841, 2005.

Chan, M. N., Lee, A. K. Y., and Chan, C. K.: Responses of ammonium sulfate particles coated with glutaric acid to cyclic changes in relative humidity: Hygroscopicity and Raman characterization, Environ. Sci. Technol., 40, 6983-6989, doi:10.1021/es060928c, 2006.

Chan, M. N. and Chan, C. K.: Mass transfer effects in hygroscopic measurements of aerosol particles, Atmos. Chem. Phys., 5, 2703-2712, doi:10.5194/acp-5-2703-2005, 2005.

Charlson, R. J., Schwartz, S. E., Hales, J. M., Cess, R. D., Coakley, J. A., Hansen, J. E., and Hofmann, D. J.: Climate forcing by anthropogenic aerosols, Science, 255, 423-430, doi:10.1126/science.255.5043.423, 1992.

Claeys, M., Kourtchev, I., Pashynska, V., Vas, G., Vermeylen, R., Wang, W., Cafmeyer, J., Chi, X., Artaxo, P., Andreae, M. O., and Maenhaut, W.: Polar organic marker compounds in atmospheric aerosols during the IBA-SMOCC 2002 biomass burning experiment in Rondônia, Brazil: sources and source processes, time series, diel variations and size distributions, Atmos. Chem. Phys., 10, 9319-9331, doi:10.5194/acp-10-9319-2010, 2010.

Clegg, S. L., Pitzer, K. S., and Brimblecombe, P.: thermodynamics of multicomponent, miscible, ionic-solutions electrolytes, 2. mixtures including unsymmetrical electrolytes, J. Phys. Chem., 96, 9470-9479, doi:10.1021/j100202a074, 1992.

Clegg, S. L., Seinfeld, J. H., and Brimblecombe, P.: Thermodynamic modelling of aqueous aerosols containing electrolytes and dissolved organic compounds, J. Aerosol Sci., 32, 713-738, doi:10.1016/s0021-8502(00)00105-1, 2001.

Clegg, S. L., Seinfeld, J. H., and Edney, E. O.: Thermodynamic modelling of aqueous aerosols containing electrolytes and dissolved organic compounds. II. An extended ZdanovskiiStokes-Robinson approach, J. Aerosol Sci., 34, 667-690, doi:10.1016/s0021-8502(03)00019-3, 2003.

Clegg, S. L., and Seinfeld, J. H.: Thermodynamic models of aqueous solutions containing inorganic electrolytes and dicarboxylic acids at 298.15 K. 2. Systems including dissociation equilibria, J. Phys. Chem. A, 110, 5718-5734, doi:10.1021/jp056150j, 2006a. 
Clegg, S. L. and Seinfeld, J. H.: Thermodynamic models of aqueous solutions containing in-organic electrolytes and dicarboxylic acids at 298.15 K. 2. Systems including dissociation equilibria, J. Phys. Chem. A, 110, 5718-5734, doi:10.1021/jp056150j, $2006 \mathrm{~b}$.

Clegg, S. L., and Wexler, A. S.: Densities and apparent molar volumes of atmospherically important electrolyte solutions. 2 . The systems $\mathrm{H}^{+}-\mathrm{HSO}_{4}-\mathrm{SO}_{4}^{2-}-\mathrm{H}_{2} \mathrm{O}$ from 0 to $3 \mathrm{~mol} \mathrm{~kg}^{-1}$ as a function of temperature and $\mathrm{H}^{+}-\mathrm{NH}_{4}^{+}-\mathrm{HSO}_{4}^{-}-\mathrm{SO}_{4}^{2-}-\mathrm{H}_{2} \mathrm{O}$ from 0 to $6 \mathrm{~mol} \mathrm{~kg}{ }^{-1}$ at 25 degrees $\mathrm{C}$ using a Pitzer ion interaction model, and $\mathrm{NH}_{4} \mathrm{HSO}_{4}-\mathrm{H}_{2} \mathrm{O}$ and $\left(\mathrm{NH}_{4}\right)_{3} \mathrm{H}\left(\mathrm{SO}_{4}\right)_{2}-\mathrm{H}_{2} \mathrm{O}$ over the entire concentration range, The J. Phys. Chem. A, 115, 3461-3474, doi:10.1021/jp1089933, 2011a.

Clegg, S. L., and Wexler, A. S.: Densities and Apparent Molar Volumes of Atmospherically Important Electrolyte Solutions. 1. The Solutes $\mathrm{H}_{2} \mathrm{SO}_{4}, \mathrm{HNO}_{3}, \mathrm{HCl}, \mathrm{Na}_{2} \mathrm{SO}_{4}, \mathrm{NaNO}_{3}, \mathrm{NaCl}$, $\left(\mathrm{NH}_{4}\right)_{2} \mathrm{SO}_{4}, \mathrm{NH}_{4} \mathrm{NO}_{3}$, and $\mathrm{NH}_{4} \mathrm{Cl}$ from 0 to 50 degrees $\mathrm{C}$, Including Extrapolations to Very Low Temperature and to the Pure Liquid State, and $\mathrm{NaHSO}_{4}, \mathrm{NaOH}$, and $\mathrm{NH}_{3}$ at 25 degrees $\mathrm{C}$, J. Phys. Chem. A, 115, 3393-3460, doi:10.1021/jp108992a, 2011 b.

Cruz, C. N. and Pandis, S. N.: The effect of organic coatings on the cloud condensation nuclei activation of inorganic atmospheric aerosol, J. Geophys. Res.-Atmos., 103, 13111-13123, doi:10.1029/98jd00979, 1998.

Decesari, S., Facchini, M. C., Matta, E., Mircea, M., Fuzzi, S., Chughtai, A. R., and Smith, D. M.: Water soluble organic compounds formed by oxidation of soot, Atmos. Environ., 36, 18271832, doi:10.1016/s1352-2310(02)00141-3, 2002.

Decesari, S., Fuzzi, S., Facchini, M. C., Mircea, M., Emblico, L., Cavalli, F., Maenhaut, W., Chi, X., Schkolnik, G., Falkovich, A., Rudich, Y., Claeys, M., Pashynska, V., Vas, G., Kourtchev, I., Vermeylen, R., Hoffer, A., Andreae, M. O., Tagliavini, E., Moretti, F., and Artaxo, P.: Characterization of the organic composition of aerosols from Rondônia, Brazil, during the LBASMOCC 2002 experiment and its representation through model compounds, Atmos. Chem. Phys., 6, 375-402, doi:10.5194/acp6-375-2006, 2006.

Dick, W. D., Saxena, P., and McMurry, P. H.: Estimation of water uptake by organic compounds in submicron aerosols measured during the Southeastern Aerosol and Visibility Study, J. Geophys. Res.-Atmos., 105, 1471-1479, doi:10.1029/1999jd901001, 2000.

Dinar, E., Mentel, T. F., and Rudich, Y.: The density of humic acids and humic like substances (HULIS) from fresh and aged wood burning and pollution aerosol particles, Atmos. Chem. Phys., 6, 5213-5224, doi:10.5194/acp-6-5213-2006, 2006a.

Dinar, E., Taraniuk, I., Graber, E. R., Katsman, S., Moise, T., Anttila, T., Mentel, T. F., and Rudich, Y.: Cloud Condensation Nuclei properties of model and atmospheric HULIS, Atmos. Chem. Phys., 6, 2465-2482, doi:10.5194/acp-6-2465-2006, $2006 b$.

Dinar, E., Taraniuk, I., Graber, E. R., Anttila, T., Mentel, T. F., and Rudich, Y.: Hygroscopic growth of atmospheric and model humic-like substances, J. Geophys. Res., 112, doi:10.1029/2006jd007442, 2007.

Djikaev, Y. S., Bowles, R., Reiss, H., Hameri, K., Laaksonen, A., and Vakeva, M.: Theory of size dependent deliquescence of nanoparticles: Relation to heterogeneous nucleation and comparison with experiments, J. Phys. Chem. B, 105, 7708-7722, doi:10.1021/jp010537e, 2001.
Dusek, U., Frank, G. P., Massling, A., Zeromskiene, K., Iinuma, Y., Schmid, O., Helas, G., Hennig, T., Wiedensohler, A., and Andreae, M. O.: Water uptake by biomass burning aerosol at suband supersaturated conditions: closure studies and implications for the role of organics, Atmos. Chem. Phys., 11, 9519-9532, doi:10.5194/acp-11-9519-2011, 2011.

Engling, G., Lee, J. J., Sie, H.-J., Wu, Y.-C., and I, Y.P.: Anhydrosugar characteristics in biomass smoke aerosolcase study of environmental influence on particle-size of rice straw burning aerosol, J. Aerosol Sci., 56, 2-14, doi:10.1016/j.jaerosci.2012.10.001, 2013.

Fors, E. O., Rissler, J., Massling, A., Svenningsson, B., Andreae, M. O., Dusek, U., Frank, G. P., Hoffer, A., Bilde, M., Kiss, G., Janitsek, S., Henning, S., Facchini, M. C., Decesari, S., and Swietlicki, E.: Hygroscopic properties of Amazonian biomass burning and European background HULIS and investigation of their effects on surface tension with two models linking $\mathrm{H}$ TDMA to CCNC data, Atmos. Chem. Phys., 10, 5625-5639, doi:10.5194/acp-10-5625-2010, 2010.

Fredenslund, A., Jones, R. L., and Prausnitz, J. M.: Group-contribution estimation of activity-coefficients in nonideal liquid-mixtures, Aiche J., 21, 1086-1099, doi:10.1002/aic.690210607, 1975.

Frosch, M., Prisle, N. L., Bilde, M., Varga, Z., and Kiss, G.: Joint effect of organic acids and inorganic salts on cloud droplet activation, Atmos. Chem. Phys., 11, 3895-3911, doi:10.5194/acp11-3895-2011, 2011.

Fu, P. Q., Kawamura, K., and Barrie, L. A.: Photochemical and Other Sources of Organic Compounds in the Canadian High Arctic Aerosol Pollution during Winter-Spring, Environ. Sci. Technol., 43, 286-292, doi:10.1021/es803046q, 2009.

Fuzzi, S., Decesari, S., Facchini, M. C., Matta, E., Mircea, M., and Tagliavini, E.: A simplified model of the water soluble organic component of atmospheric aerosols, Geophys. Res. Lett., 28, 4079-4082, doi:10.1029/2001g1013418, 2001.

Gysel, M., Weingartner, E., and Baltensperger, U.: Hygroscopicity of aerosol particles at low temperatures. 2. Theoretical and experimental hygroscopic properties of laboratory generated aerosols, Environ. Sci. Technol., 36, 63-68, doi:10.1021/es010055g, 2002.

Gysel, M., Weingartner, E., Nyeki, S., Paulsen, D., Baltensperger, U., Galambos, I., and Kiss, G.: Hygroscopic properties of watersoluble matter and humic-like organics in atmospheric fine aerosol, Atmos. Chem. Phys., 4, 35-50, doi:10.5194/acp-4-352004, 2004.

Ha, Z. Y. and Chan, C. K.: The water activities of $\mathrm{MgCl} 2$, $\mathrm{Mg}(\mathrm{NO} 3)(2), \mathrm{MgSO}_{4}$, and their mixtures, Aerosol Sci. Technol., 31, 154-169, doi:10.1080/027868299304219, 1999.

Hameri, K., Vakeva, M., Hansson, H. C., and Laaksonen, A.: Hygroscopic growth of ultrafine ammonium sulphate aerosol measured using an ultrafine tandem differential mobility analyzer, J. Geophys. Res.-Atmos., 105, 22231-22242, doi:10.1029/2000jd900220, 2000.

Hameri, K., Charlson, R., and Hansson, H. C.: Hygroscopic properties of mixed ammonium sulfate and carboxylic acids particles, Aiche J., 48, 1309-1316, doi:10.1002/aic.690480617, 2002.

Hanford, K. L., Mitchem, L., Reid, J. P., Clegg, S. L., Topping, D. O., and McFiggans, G. B.: Comparative thermodynamic studies of aqueous glutaric acid, ammonium sulfate and sodium chlo- 
ride aerosol at high humidity, J. Phys. Chem. A, 112, 9413-9422, doi:10.1021/jp802520d, 2008.

Hansen, H. K., Rasmussen, P., Fredenslund, A., Schiller, M., and Gmehling, J.: Vapor-liquid equilibria by UNIFAC group contribution. 5. Revision and extension, Ind. Eng. Chem. Res., 30, 2352-2355, doi:10.1021/ie00058a017, 1991.

Heintzenberg, J. and Charlson, R. J. (Eds.): Clouds in the perturbed climate system: their relationship to energy balance, atmospheric dynamics, and precipitation, Struengmann Forum Report, vol. 2., The MIT Press, Cambridge, MA, USA, 2009.

Henning, S., Rosenørn, T., D’Anna, B., Gola, A. A., Svenningsson, B., and Bilde, M.: Cloud droplet activation and surface tension of mixtures of slightly soluble organics and inorganic salt, Atmos. Chem. Phys., 5, 575-582, doi:10.5194/acp-5-575-2005, 2005.

Henning, S., Wex, H., Hennig, T., Kiselev, A., Snider, J. R., Rose, D., Dusek, U., Frank, G. P., Pöschl, U., Kristensson, A., Bilde, M., Tillmann, R., Kiendler-Scharr, A., Mentel, T. F., Walter, S., Schneider, J., Wennrich, C., and Stratmann, F.: Soluble mass, hygroscopic growth, and droplet activation of coated soot particles during LACIS Experiment in November (LExNo), J. Geophys. Res., 115, doi:10.1029/2009jd012626, 2010.

Hersey, S. P., Craven, J. S., Metcalf, A. R., Lin, J., Lathem, T., Suski, K. J., Cahill, J. F., Duong, H. T., Sorooshian, A., Jonsson, H. H., Shiraiwa, M., Zuend, A., Nenes, A., Prather, K. A., Flagan, R. C., and Seinfeld, J. H.: Composition and hygroscopicity of the Los Angeles Aerosol: CalNex, J. Geophys. Res.-Atmos., 118, 30163036, doi:10.1002/jgrd.50307, 2013.

Hoffer, A., Gelencsér, A., Guyon, P., Kiss, G., Schmid, O., Frank, G. P., Artaxo, P., and Andreae, M. O.: Optical properties of humic-like substances (HULIS) in biomass-burning aerosols, Atmos. Chem. Phys., 6, 3563-3570, doi:10.5194/acp-6-35632006, 2006.

Iinuma, Y., Brüggemann, E., Gnauk, T., Müller, K., Andreae, M. O., Helas, G., Parmar, R., and Herrmann, H.: Source characterization of biomass burning particles: The combustion of selected European conifers, African hardwood, savanna grass, and German and Indonesian peat, J. Geophys. Res., 112, doi:10.1029/2006jd007120, 2007.

Jedelsky, J., Hnedkovskí, L., Hyncica, P., and Cibulka, I.: Partial molar volumes of organic solutes in water. IV. Benzoic and hydroxybenzoic acids at temperatures from $\mathrm{T}=298 \mathrm{~K}$ to $\mathrm{T}=498$ $\mathrm{K}$ and pressures up to 30MPa, J. Chem. Thermodyn., 32, 1299 1310, 2000.

Jokinen, V., and Makela, J. M.: Closed-loop arrangement with critical orifice for DMA sheath excess flow system, J. Aerosol Sci., 28, 643-648, doi:10.1016/s0021-8502(96)00457-0, 1997.

Jung, J., and Kim, Y. J.: Tracking sources of severe haze episodes and their physicochemical and hygroscopic properties under Asian continental outflow: Long-range transport pollution, postharvest biomass burning, and Asian dust, J. Geophys. Res., 116, doi:10.1029/2010jd014555, 2011.

Jung, J., Kim, Y. J., Aggarwal, S. G., and Kawamura, K.: Hygroscopic property of water-soluble organic-enriched aerosols in Ulaanbaatar, Mongolia during the cold winter of 2007, Atmos. Environ., 45, 2722-2729, doi:10.1016/j.atmosenv.2011.02.055, 2011a.

Jung, J. S., Kim, Y. J., Aggarwal, S. G., and Kawamura, K.: Hygroscopic property of water-soluble organic-enriched aerosols in Ulaanbaatar, Mongolia during the cold winter of 2007, Atmos.
Environ., 45, 2722-2729, doi:10.1016/j.atmosenv.2011.02.055, 2011b.

Kerminen, V. M.: The effects of particle chemical character and atmospheric processes on particle hygroscopic properties, J. Aerosol Sci., 28, 121-132, doi:10.1016/s0021-8502(96)000699, 1997.

Kiss, G., Tombácz, E., and Hansson, H.-C.: Surface Tension Effects of Humic-Like Substances in the Aqueous Extract of Tropospheric Fine Aerosol, J. Atmos. Chem., 50, 279-294, doi:10.1007/s10874-005-5079-5, 2005.

Koehler, K. A., Kreidenweis, S. M., DeMott, P. J., Prenni, A. J., Carrico, C. M., Ervens, B., and Feingold, G.: Water activity and activation diameters from hygroscopicity data - Part II: Application to organic species, Atmos. Chem. Phys., 6, 795-809, doi:10.5194/acp-6-795-2006, 2006

Kreidenweis, S. M., Koehler, K., DeMott, P. J., Prenni, A. J., Carrico, C., and Ervens, B.: Water activity and activation diameters from hygroscopicity data - Part I: Theory and application to inorganic salts, Atmos. Chem. Phys., 5, 1357-1370, doi:10.5194/acp-5-1357-2005, 2005.

Lienhard, D. M., Bones, D. L., Zuend, A., Krieger, U. K., Reid, J. P., and Peter, T.: Measurements of thermodynamic and optical properties of selected aqueous organic and organic-inorganic mixtures of atmospheric relevance, The J. Phys. Chem.. A, 116, 9954-9968, doi:10.1021/jp3055872, 2012.

Lightstone, J. M., Onasch, T. B., Imre, D., and Oatis, S.: Deliquescence, efflorescence, and water activity in ammonium nitrate and mixed ammonium nitrate/succinic acid microparticles, J. Phys. Chem. A, 104, 9337-9346, doi:10.1021/jp002137h, 2000.

Lohmann, U. and Feichter, J.: Global indirect aerosol effects: a review, Atmos. Chem. Phys., 5, 715-737, doi:10.5194/acp-5-7152005, 2005.

Malm, W. C., and Kreidenweis, S. M.: The effects of models of aerosol hygroscopicity on the apportionment of extinction, Atmos. Environ., 31, 1965-1976, doi:10.1016/s13522310(96)00355-x, 1997.

Marcolli, C. B. L. and Peter, T.: Mixing of the organic aerosol fractions: liquids as the thermodynamically stable phases, J. Phys. Chem. A, 108, 2216-2224, 2004.

Martin, S. T., Andreae, M. O., Artaxo, P., Baumgardner, D., Chen, Q., Goldstein, A. H., Guenther, A., Heald, C. L., MayolBracero, O. L., McMurry, P. H., Pauliquevis, T., Pöschl, U., Prather, K. A., Roberts, G. C., Saleska, S. R., Silva Dias, M. A., Spracklen, D. V., Swietlicki, E., and Trebs, I.: Sources and properties of Amazonian aerosol particles, Rev. Geophys., 48, doi:10.1029/2008rg000280, 2010.

Maskey, S., Chong, K. Y., Kim, G., Kim, J.-S., Ali, A., and Park, K.: Effect of mixing structure on the hygroscopic behavior of ultrafine ammonium sulfate particles mixed with succinic acid and levoglucosan, Particuology, 13, 27-34, doi:10.1016/j.partic.2013.08.004, 2014.

Mikhailov, E., Vlasenko, S., Niessner, R., and Pöschl, U.: Interaction of aerosol particles composed of protein and saltswith water vapor: hygroscopic growth and microstructural rearrangement, Atmos. Chem. Phys., 4, 323-350, doi:10.5194/acp-4-323-2004, 2004.

Mikhailov, E., Vlasenko, S., Martin, S. T., Koop, T., and Pöschl, U.: Amorphous and crystalline aerosol particles interacting with water vapor: conceptual framework and experimental evidence 
for restructuring, phase transitions and kinetic limitations, Atmos. Chem. Phys., 9, 9491-9522, doi:10.5194/acp-9-9491-2009, 2009.

Mikhailov, E. F., Vlasenko, S. S., and Ryshkevich, T. I.: Influence of chemical composition and microstructure on the hygroscopic growth of pyrogenic aerosol, Izvestiya, Atmos. Ocean. Phys., 44, 416-431, doi:10.1134/s0001433808040038, 2008.

Mirabel, P., Reiss, H., and Bowles, R. K.: A theory for the deliquescence of small particles, J. Chem. Phys., 113, 8200-8205, doi:10.1063/1.1315993, 2000.

Mochida, M. and Kawamura, K.: Hygroscopic properties of levoglucosan and related organic compounds characteristic to biomass burning aerosol particles, J. Geophys. Res.-Atmos., 109, D21202, doi:10.1029/2004jd004962, 2004.

Narukawa, M., Kawamura, K., Takeuchi, N., and Nakajima, T.: Distribution of dicarboxylic acids and carbon isotopic compositions in aerosols from 1997 Indonesian forest fires, Geophys. Res. Lett., 26, 3101-3104, doi:10.1029/1999g1010810, 1999.

Novakov, T., and Corrigan, C. E.: Cloud condensation nucleus activity of the organic component of biomass smoke particles, Geophys. Res. Lett., 23, 2141-2144, doi:10.1029/96g101971, 1996.

Onasch, T. B., Siefert, R. L., Brooks, S. D., Prenni, A. J., Murray, B., Wilson, M. A., and Tolbert, M. A.: Infrared spectroscopic study of the deliquescence and efflorescence of ammonium sulfate aerosol as a function of temperature, J. Geophys. Res.-Atmos., 104, 21317-21326, doi:10.1029/1999jd900384, 1999.

Pöschl, U.: Atmospheric Aerosols: Composition, Transformation, Climate and Health Effects, Angewandte Chemie International Edition, 44, 7520-7540, doi:10.1002/anie.200501122, 2005.

Pandis, S. N., Wexler, A. S., and Seinfeld, J. H.: Dynamics of tropospheric Aerosols, J. Phys. Chem., 99, 9646-9659, doi:10.1021/j100024a003, 1995.

Peng, C., Chan, M. N., and Chan, C. K.: The hygroscopic properties of dicarboxylic and multifunctional acids: measurements and UNIFAC predictions, Environ. Sci. Technol., 35, 4495-4501, 2001.

Petters, M. D., Carrico, C. M., Kreidenweis, S. M., Prenni, A. J., DeMott, P. J., Collett, J. L., and Moosmüller, H.: Cloud condensation nucleation activity of biomass burning aerosol, J. Geophys. Res., 114, doi:10.1029/2009jd012353, 2009.

Pilinis, C., Pandis, S. N., and Seinfeld, J. H.: sensitivity of direct climate forcing by atmospheric aerosols to aerosol-size and composition, J. Geophys. Res.-Atmos., 100, 18739-18754, doi:10.1029/95jd02119, 1995.

Pope, F. D., Dennis-Smither, B. J., Griffiths, P. T., Clegg, S. L., and Cox, R. A.: Studies of Single Aerosol Particles Containing Malonic Acid, Glutaric Acid, and Their Mixtures with Sodium Chloride. I. Hygroscopic Growth, J. Phys. Chem. A, 114, 5335-5341, doi:10.1021/jp100059k, 2010a.

Pope, F. D., Harper, L., Dennis-Smither, B. J., Griffiths, P. T., Clegg, S. L., and Cox, R. A.: Laboratory and modelling study of the hygroscopic properties of two model humic acid aerosol particles, J. Aerosol Sci., 41, 457-467, doi:10.1016/j.jaerosci.2010.02.012, 2010b.

Psichoudaki, M. and Pandis, S. N.: Atmospheric aerosol watersoluble organic carbon measurement: a theoretical analysis, Environ. Sci. Technol., 47, 9791-9798, doi:10.1021/es402270y, 2013.
Raymond, T. M. and Pandis, S. N.: Cloud activation of singlecomponent organic aerosol particles, J. Geophys. Res.-Atmos., 107, doi:10.1029/2002jd002159, 2002.

Rissler, J., Vestin, A., Swietlicki, E., Fisch, G., Zhou, J., Artaxo, P., and Andreae, M. O.: Size distribution and hygroscopic properties of aerosol particles from dry-season biomass burning in Amazonia, Atmos. Chem. Phys., 6, 471-491, 2006, http://www.atmos-chem-phys.net/6/471/2006/.

Rissler, J., Svenningsson, B., Fors, E. O., Bilde, M., and Swietlicki, E.: An evaluation and comparison of cloud condensation nucleus activity models: Predicting particle critical saturation from growth at subsaturation, J. Geophys. Res., 115, doi:10.1029/2010jd014391, 2010.

Roberts, G. C., Andreae, M. O., Maenhaut, W., and FernandezJimenez, M. T.: Composition and sources of aerosol in a central African rain forest during the dry season, J. Geophys. Res.Atmos., 106, 14423-14434, doi:10.1029/2000jd900774, 2001.

Roberts, G. C., Artaxo, P., Zhou, J. C., Swietlicki, E., and Andreae, M. O.: Sensitivity of CCN spectra on chemical and physical properties of aerosol: a case study from the Amazon Basin, J. Geophys. Res.-Atmos., 107, 8070, doi:10.1029/2001jd000583, 2002.

Roberts, G. C., Nenes, A., Seinfeld, J. H., and Andreae, M. O.: Impact of biomass burning on cloud properties in the Amazon Basin, J. Geophys. Res.-Atmos., 108, 4062, doi:10.1029/2001jd000985, 2003.

Ruellan, S., Cachier, H., Gaudichet, A., Masclet, P., and Lacaux, J. P.: Airborne aerosols over central Africa during the experiment for regional sources and sinks of oxidants (EXPRESSO), J. Geophys. Res.-Atmos., 104, 30673-30690, doi:10.1029/1999jd900804, 1999.

Russell, L. M., and Ming, Y.: Deliquescence of small particles, J. Chem. Phys., 116, 311-321, doi:10.1063/1.1420727, 2002.

Samburova, V., Hallar, A. G., Mazzoleni, L. R., Saranjampour, P., Lowenthal, D., Kohl, S. D., and Zielinska, B.: Composition of water-soluble organic carbon in non-urban atmospheric aerosol collected at the Storm Peak Laboratory, Environ. Chem., 10, 370, doi:10.1071/en13079, 2013.

Schultz, M. G., Heil, A., Hoelzemann, J. J., Spessa, A., Thonicke, K., Goldammer, J. G., Held, A. C., Pereira, J. M. C., and van het Bolscher, M.: Global wildland fire emissions from 1960 to 2000, Glob. Biogeochem. Cy., 22, GB2002, doi:10.1029/2007GB003031, 2008.

Shamjad, P. M, Tripathi, S. N, Aggarwal, S. G, Mishra, S. G, Joshi, Manish, Khan, Arshad, Sapra, B. K and Ram, Kipra.: Comparison of Experimental and Modeled Absorption Enhancement by Black Carbon (BC) Cored Polydisperse Aerosols under Hygroscopic Conditions, Environ. Sci. Technol., 46, 8082-8089, 2012.

Shi, Y. J., Ge, M. F., and Wang, W. G.: Hygroscopicity of internally mixed aerosol particles containing benzoic acid and inorganic salts, Atmos. Environ., 60, 9-17, doi:10.1016/j.atmosenv.2012.06.034, 2012.

Shiraiwa, M., Zuend, A., Bertram, A. K., and Seinfeld, J. H.: Gasparticle partitioning of atmospheric aerosols: interplay of physical state, non-ideal mixing and morphology, Phys. Chem. Chem. Phys., 15, 11441-11453, doi:10.1039/c3cp51595h, 2013.

Shimmo, M., Anttila, P., Hartonen, K., Hyotylainen, T., Paatero,J., Kulmala, M., and Riekkola, M-L.: Identification of organic compounds in atmsopheric aerosol particles by on- 
line supercritical fluid extraction-liquid chromatography-gas chromatography-mass spectrometer, J. Chromat., 151-159, 2004.

Sjogren, S., Gysel, M., Weingartner, E., Baltensperger, U., Cubison, M. J., Coe, H., Zardini, A. A., Marcolli, C., Krieger, U. K., and Peter, T.: Hygroscopic growth and water uptake kinetics of two-phase aerosol particles consisting of ammonium sulfate, adipic and humic acid mixtures, J. Aerosol Sci., 38, 157-171, doi:10.1016/j.jaerosci.2006.11.005, 2007.

Sloane, C. S., and Wolff, G. T.: Prediction of ambient lightscattering using a physical model responsive to relativehumidity-validation with measurements from detroit, Atmos. Environ., 19, 669-680, doi:10.1016/0004-6981(85)90046-0, 1985.

Song, M., Marcolli, C., Krieger, U. K., Zuend, A., and Peter, T.: Liquid-liquid phase separation and morphology of internally mixed dicarboxylic acids/ammonium sulfate/water particles, Atmos. Chem. Phys., 12, 2691-2712, doi:10.5194/acp-12-26912012, 2012.

Stokes, R. H. and Robinson, R. A.: Interactions in aqueous nonelectrolyte solutions. I. Solute-solvent equilibria, J. Phys. Chem., 70, 2126-2130, 1966.

Stolzenburg, M. R., and McMurry, P. H.: Equations governing single and tandem DMA configurations and a new lognormal approximation to the transfer function, Aerosol Sci. Technol., 42, 421-432, doi:10.1080/02786820802157823, 2008.

Svenningsson, B., Rissler, J., Swietlicki, E., Mircea, M., Bilde, M., Facchini, M. C., Decesari, S., Fuzzi, S., Zhou, J., Mønster, J., and Rosenørn, T.: Hygroscopic growth and critical supersaturations for mixed aerosol particles of inorganic and organic compounds of atmospheric relevance, Atmos. Chem. Phys., 6, 1937-1952, doi:10.5194/acp-6-1937-2006, 2006.

Tuckermann, R. and Cammenga, H. K.: The surface tension of aqueous solutions of some atmospheric water-soluble organic compounds, Atmos. Environ., 38, 6135-6138, 2004.

van der Werf, G. R., Randerson, J. T., Giglio, L., Collatz, G. J., Kasibhatla, P. S., and Arellano Jr., A. F.: Interannual variability in global biomass burning emissions from 1997 to 2004, Atmos. Chem. Phys., 6, 3423-3441, doi:10.5194/acp-6-3423-2006, 2006.

Vestin, A., Rissler, J., Swietlicki, E., Frank, G. P., and Andreae, M. O.: Cloud-nucleating properties of the Amazonian biomass burning aerosol: Cloud condensation nuclei measurements and modeling, J. Geophys. Res., 112, doi:10.1029/2006jd008104, 2007.

Wise, M. E, Surratt, J. D, Curtis, D. B, Shilling, J. E, and Tolbert, M. A.: Hygroscopic growth of ammonium sulfate/dicarboxylic acids, J. Geophys. Res., 108, 4638, doi:10.1029/2003JD003775, 2003.

Wu, Z. J., Nowak, A., Poulain, L., Herrmann, H., and Wiedensohler, A.: Hygroscopic behavior of a tmospherically relevant watersoluble carboxylic salts and their influence on the water uptake of ammonium sulfate, Atmos. Chem. Phys., 11, 12617-12626, doi:10.5194/acp-11-12617-2011, 2011.
Yates III, L. M. and Wandruszka, R. V.: Decontamination of polluted water by treatment with a crude humic acid blend, Environ. Sci. Technol., 33, 2076-2080, 1999.

Yeung, M. C., and Chan, C. K.: Water Content and Phase Transitions in Particles of Inorganic and Organic Species and their Mixtures Using Micro-Raman Spectroscopy, Aerosol Sci. Technol., 44, 269-280, doi:10.1080/02786820903583786, 2010.

Zamora, I. R., Tabazadeh, A., Golden, D. M., and Jacobson, M. Z.: Hygroscopic growth of common organic aerosol solutes, including humic substances, as derived from water activity measurements, J. Geophys. Res.-Atmos., 116, n/a-n/a, doi:10.1029/2011jd016067, 2011.

Zamora, I. R. and Jacobson, M. Z.: Measuring and modeling the hygroscopic growth of two humic substances in mixed aerosol particles of atmospheric relevance, Atmos. Chem. Phys., 13, 89738989, doi:10.5194/acp-13-8973-2013, 2013.

Zardini, A. A., Sjogren, S., Marcolli, C., Krieger, U. K., Gysel, M., Weingartner, E., Baltensperger, U., and Peter, T.: A combined particle trap/HTDMA hygroscopicity study of mixed inorganic/organic aerosol particles, Atmos. Chem. Phys., 8, 55895601, doi:10.5194/acp-8-5589-2008, 2008.

Zhang, Y. H., and Chan, C. K.: Study of contact ion pairs of supersaturated magnesium sulfate solutions using raman scattering of levitated single droplets, J. Phys. Chem. A, 104, 9191-9196, doi:10.1021/jp0013659, 2000.

Zuend, A., Marcolli, C., Luo, B. P., and Peter, T.: A thermodynamic model of mixed organic-inorganic aerosols to predict activity coefficients, Atmos. Chem. Phys., 8, 4559-4593, doi:10.5194/acp8-4559-2008, 2008.

Zuend, A., Marcolli, C., Peter, T., and Seinfeld, J. H.: Computation of liquid-liquid equilibria and phase stabilities: implications for RH-dependent gas/particle partitioning of organic-inorganic aerosols, Atmos. Chem. Phys., 10, 7795-7820, doi:10.5194/acp10-7795-2010, 2010.

Zuend, A., Marcolli, C., Booth, A. M., Lienhard, D. M., Soonsin, V., Krieger, U. K., Topping, D. O., McFiggans, G., Peter, T., and Seinfeld, J. H.: New and extended parameterization of the thermodynamic model AIOMFAC: calculation of activity coefficients for organic-inorganic mixtures containing carboxyl, hydroxyl, carbonyl, ether, ester, alkenyl, alkyl, and aromatic functional groups, Atmos. Chem. Phys., 11, 9155-9206, doi:10.5194/acp11-9155-2011, 2011.

Zuend, A., and Seinfeld, J. H.: Modeling the gas-particle partitioning of secondary organic aerosol: the importance of liquidliquid phase separation, Atmos. Chem. Phys., 12, 3857-3882, doi:10.5194/acp-12-3857-2012, 2012.

Zuend, A., and Seinfeld, J. H.: A practical method for the calculation of liquid-liquid equilibria in multicomponent organic-water-electrolyte systems using physicochemical constraints, Fluid Phase Equilibria, 337, 201-213, doi:10.1016/j.fluid.2012.09.034, 2013. 